\title{
Structural Chemistry and Magnetic Properties of $\mathrm{Nd}_{18} \mathrm{Li}_{8} \mathrm{Fe}_{5-x} \mathrm{M}_{x} \mathrm{O}_{39}$ $(\mathrm{M}=\mathrm{Mn}, \mathrm{Co})$
}

\author{
Siân E. Dutton, ${ }^{\dagger}$ Peter D. Battle, ${ }^{, \dagger}$ Fernande Grandjean, ${ }^{\ddagger}$ Gary J. Long, ${ }^{,, \S}$ and Peter A. van \\ Daesdonk $^{\dagger}$
}

Inorganic Chemistry Laboratory, Department of Chemistry, University of Oxford, South Parks Road, Oxford, OX1 3QR, United Kingdom, Department of Physics, University of Liège, B5, B-4000 Sart-Tilman, Belgium, and Department of Chemistry, Missouri University of Science and Technology, University of Missouri-Rolla, Rolla, Missouri 65409-0010

Received October 23, 2008

\begin{abstract}
Polycrystalline samples of $\mathrm{Nd}_{18} \mathrm{Li}_{8} \mathrm{Fe}_{5-x} \mathrm{M}_{x} \mathrm{O}_{39}(\mathrm{M}=\mathrm{Mn}, 0<x \leq 4 ; \mathrm{M}=\mathrm{Co} ; 0<x \leq 3)$ have been synthesized using a solid-state method and have been studied using a combination of $\mathrm{dc}$ and ac magnetometry, neutron diffraction, and Mössbauer spectroscopy. All compositions adopt a cubic structure (space group $P m \overline{3} n, a_{0} \sim 11.9$ $\AA$ ) based on intersecting $<111>$ chains made up of alternating octahedral and trigonal-prismatic coordination sites. These chains occupy channels within a $\mathrm{Nd}-\mathrm{O}$ framework. The trigonal prismatic site is occupied by $\mathrm{Li}^{+}$and, in some cases, high-spin $\mathrm{Fe}^{3+}$. When $\mathrm{M}=\mathrm{Mn}$, the smaller of the two distinct octahedral sites in the structure is occupied by a disordered distribution of $\mathrm{Mn}^{4+}$ and low-spin $\mathrm{Fe}^{4+}$, but in $\mathrm{Nd}_{18} \mathrm{Li}_{8} \mathrm{Fe}_{4} \mathrm{CoO}_{39}$, this site is occupied exclusively by $\mathrm{Fe}^{4+}$. The larger of the octahedral sites is occupied by a disordered distribution of $\mathrm{M}^{3+}$, high-spin $\mathrm{Fe}^{3+}$, and, in some cases, $\mathrm{Li}^{+}$. Unusually, the $\mathrm{Mn}^{3+}$ cations in $\mathrm{Nd}_{18} \mathrm{Li}_{8} \mathrm{Fe}_{5-x} \mathrm{M}_{x} \mathrm{O}_{39}$ adopt a low-spin state. This is attributed to the presence of an internal chemical pressure generated by the $\mathrm{Nd}-\mathrm{O}$ framework. Competing magnetic superexchange interactions lead to the formation of a spin-glass-like phase in all compositions below $T_{\mathrm{f}} \sim 5 \mathrm{~K}$; the transition temperature decreases with increasing cobalt content but is relatively insensitive to the composition when $\mathrm{M}=\mathrm{Mn}$.
\end{abstract}

\section{Introduction}

The ferrimagnetism found in many spinel-structured materials stems from the ordered distribution of two species of magnetic cations over two crystallographically distinct sites. The two cations may derive from the same element, as in $\mathrm{Fe}_{3} \mathrm{O}_{4}$, or different elements, as in $\mathrm{CoCr}_{2} \mathrm{O}_{4}$. It follows that it should be possible to use other crystal structures to design new ferrimagnets, provided that they contain two sites which are sufficiently different in size or coordination geometry to ensure that an ordered cation distribution results. $\mathrm{La}_{18} \mathrm{Li}_{8} \mathrm{Rh}_{5} \mathrm{O}_{39}{ }^{1}$ adopts such a structure, as shown in Figure 1. Chains of coordination polyhedra, in which octahedral sites alternate with trigonal prismatic sites, occupy channels within

\footnotetext{
* To whom correspondence should be addressed. E-mail: Peter.Battle@ chem.ox.ac.uk (P.D.B.), glong@mst.edu (G.J.L.).

$\dagger$ University of Oxford.

University of Liège.

${ }^{\S}$ University of Missouri-Rolla.

(1) Frampton, P. P. C.; Battle, P. D.; Ritter, C. Inorg. Chem. 2005, 44, 7138.
}

a $\mathrm{La}-\mathrm{O}$ framework. The chains run along the <111> directions of the cubic unit cell and intersect each other at $(0,0,0)$ and $(1 / 2,1 / 2,1 / 2)$. Equivalent octahedral sites are located at these two points of intersection, and a further, crystallographically distinct octahedral site is located halfway between them. The two distinct types of octahedral site are always separated from each other by a prismatic site which is occupied by $\mathrm{Li}^{+}$. In $\mathrm{La}_{18} \mathrm{Li}_{8} \mathrm{Rh}_{5} \mathrm{O}_{39}$, the rhodium cations, which occur as $\mathrm{Rh}^{3+}$ and $\mathrm{Rh}^{4+}$ in a 4:1 ratio, are found respectively on the crystallographically distinct $8 e$ and $2 a$ sites of space group $\operatorname{Pm} \overline{3} n$; the $8 e$ site is significantly larger than the $2 a$ site, a size difference that drives the cation ordering. The diamagnetic electron configuration of $\mathrm{Rh}^{3+}$ ensures that $\mathrm{La}_{18} \mathrm{Li}_{8} \mathrm{Rh}_{5} \mathrm{O}_{39}$ itself is not interesting magnetically, but the observation of cation ordering suggests that the structure might support ferrimagnetism in other compositions. We began to explore this possibility by synthesizing and characterizing $\mathrm{Nd}_{18} \mathrm{Li}_{8} \mathrm{Fe}_{5} \mathrm{O}_{39}$. ${ }^{2}$ For reasons that have been discussed previously, at low temperatures, this com-

Inorganic Chemistry, Vol. 48, No. 4, 20091613 
(a)

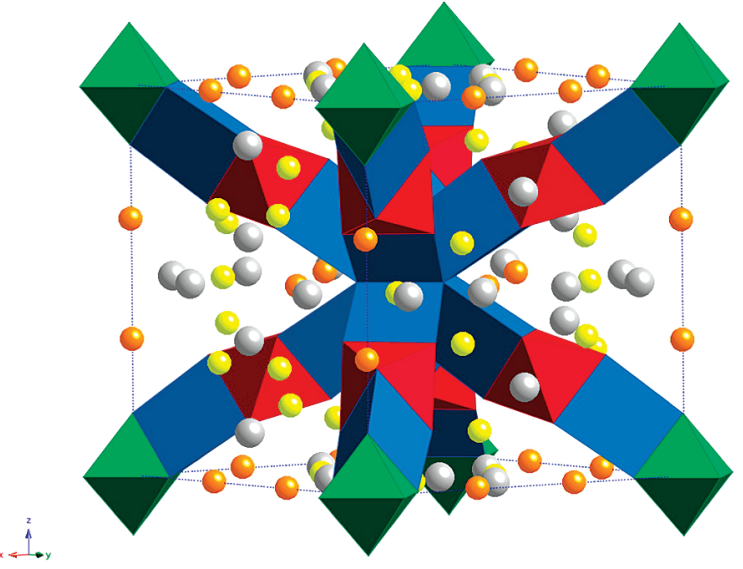

(b)

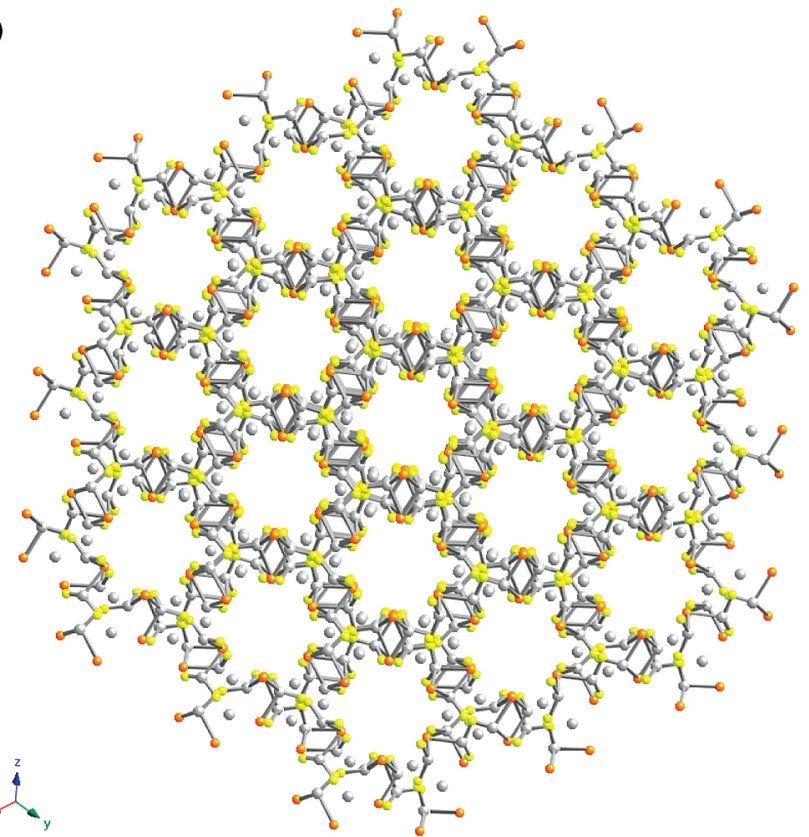

Figure 1. The $\mathrm{La}_{18} \mathrm{Li}_{8} \mathrm{Rh}_{5} \mathrm{O}_{39}$ structure. (a) The unit cell. Gray circles represent oxygen (O2 and $\mathrm{O} 3$ ), yellow circles $\mathrm{La} 1$, and orange circles $\mathrm{La} 2$. The $\mathrm{LiO}_{6}$ trigonal prisms are blue ( $16 i$ site). The $\mathrm{RhO}_{6}$ octahedra are green ( $2 a$ site) and red ( $8 e$ site). An additional $\mathrm{RhO}_{6}(2 a)$ octahedral site is located at the center of the unit cell. (b) $<111>$ view showing the $\mathrm{La}-\mathrm{O}$ channels within which lie the polyhedral chains.

pound shows spin-glass behavior rather than long-rangeordered magnetism. We describe below our study of compositions with the general formula $\mathrm{Nd}_{18} \mathrm{Li}_{8} \mathrm{Fe}_{5-x} \mathrm{M}_{x} \mathrm{O}_{39}(1 \leq$ $x \leq 4 ; \mathrm{M}=\mathrm{Mn}, \mathrm{Co}$ ). The two limiting $\mathrm{Fe} / \mathrm{M}$ ratios are consistent with complete ordering of two different elements over the two sites, rather than the ordering of aliovalent cations of the same element as in $\mathrm{Ln}_{18} \mathrm{Li}_{8} \mathrm{Fe}_{5} \mathrm{O}_{39}$. In principle, this could enhance the net magnetization observed in a ferrimagnetic phase. The intermediate compositions provide important information on the factors that determine the observed behavior.

\section{Experimental Section}

Attempts were made to synthesize pure, polycrystalline samples of $\mathrm{Nd}_{18} \mathrm{Li}_{8} \mathrm{Fe}_{5-x} \mathrm{M}_{x} \mathrm{O}_{39}(\mathrm{M}=\mathrm{Mn}, \mathrm{Co})$. Stoichiometric quantities of

(2) Dutton, S. E.; Battle, P. D.; Grandjean, F.; Long, G. J.; Oh-ishi, K. Inorg. Chem. 2008, 47, 11212. oxide starting materials [neodymium(III) oxide (99.99\%, Alfa Aesar), manganese(IV) oxide ( $99.999 \%$, Alfa Aesar), iron(III) oxide (99.998\%, Alfa Aesar), cobalt(II, III) oxide (99.9985\%, Alfa Aesar)] were ground together along with a $50 \%$ excess of the highly volatile lithium carbonate (AnalaR) prior to firing in pellet form at $800{ }^{\circ} \mathrm{C}$ in air overnight. A further $50 \%$ excess of lithium carbonate was ground into the reaction mixture before it was fired again in air for $1 \mathrm{~h}$, as a pellet, at $1000^{\circ} \mathrm{C}$. X-ray powder diffraction was used to monitor the progress of the reactions. Further $1 \mathrm{~h}$ firings, with the addition of $50 \%$ excess lithium carbonate, were carried out on samples that X-ray powder diffraction showed to be impure at this stage. No discoloration of the alumina crucible was observed in any of the reactions described herein.

All X-ray powder diffraction was carried out on a Philips X'pert diffractometer operating with $\mathrm{Cu} \mathrm{K} \alpha_{1}$ radiation with a step size of $\Delta 2 \theta=0.0084^{\circ}$. High-intensity X-ray powder diffraction data were collected over a small angular range $(15 \leq 2 \theta /$ degrees $\leq 40)$ in order to detect lithium-containing impurities. High-resolution X-ray powder diffraction data for use in quantitative analysis were collected over the angular range $5 \leq 2 \theta /$ degrees $\leq 125$. Limited Rietveld $^{3}$ refinements of the structures were carried out using the GSAS $^{4}$ suite of programs. Backgrounds were fitted using a Chebyshev polynomial of the first kind, and the peak shape was modeled using a pseudo-Voigt function.

The diffractometer D2b at the Institut Laue Langevin, Grenoble, France, was used to collect neutron powder diffraction data on selected samples. D2b is a high-flux, high-resolution instrument that operates at a wavelength, $\lambda$, of $1.59147 \AA$. Data were collected over the angular range $5 \leq 2 \theta /$ degrees $\leq 160$ with a step size $\Delta 2 \theta$ $=0.05^{\circ}$ at room temperature and, in some cases, at $3.3 \mathrm{~K}$. Samples $(\sim 0.5 \mathrm{~g})$ were contained within vanadium cans $(\phi=5 \mathrm{~mm})$ and, for the low-temperature experiments, mounted in a Displex refrigerator. Rietveld refinements of the structures were carried out using the FULLPROF ${ }^{5}$ program. Backgrounds were estimated manually and then refined using the software. Peak shapes were modeled using a pseudo-Voigt function employing three peakasymmetry parameters in the angular region $2 \theta \leq 54^{\circ}$.

Magnetic measurements were carried out using a Quantum Design MPMS 5000 SQUID magnetometer. The magnetization $(M)$ was measured as a function of temperature on warming from 2 to $300 \mathrm{~K}$ after cooling both in zero field (ZFC) and in the measuring field of $100 \mathrm{Oe}$ (FC). The isothermal magnetization was measured as a function of the field $(-50 \leq \mathrm{H} / \mathrm{kOe} \leq 50)$ after cooling to the measuring temperature at $50 \mathrm{kOe}$. AC susceptibility data were recorded at up to 11 frequencies $(0.5 \leq \omega / \mathrm{Hz} \leq 1000)$ in a direct field of $\sim 2$ Oe and an oscillating field of amplitude 3.5 Oe over an appropriate temperature range with $\Delta T=0.1 \mathrm{~K}$.

The Mössbauer spectra have been measured between 4.2 and $295 \mathrm{~K}$ in a Janis Supervaritemp cryostat with a constant-acceleration spectrometer, which utilized a rhodium matrix cobalt-57 source and was calibrated at room temperature with $\alpha$-iron powder. The Mössbauer spectral absorber contained $20 \mathrm{mg} / \mathrm{cm}^{2}$ of a powder sample mixed with boron nitride. The ideal thickness of the Mössbauer absorber is limited to this value because of the strong nonresonant scattering of the $\gamma$-rays by the 18 neodymium ions per formula unit. This effect is, at least in part, responsible for the rather low signal-to-noise ratio observed at 4.2 and $25 \mathrm{~K}$. For the $2 a$ and $8 e$ sites, the relative statistical errors associated

(3) Rietveld, H. M. J. Appl. Crystallogr. 1969, 2, 65.

(4) Larson, A. C.; von-Dreele, R. B. General Structure Analysis System (GSAS), LAUR 86-748; Los Alamos National Laboratories: Los Alamos, NM, 1994.

(5) Rodriguez-Carvajal, J. Physica B 1993, 192, 55.

1614 Inorganic Chemistry, Vol. 48, No. 4, 2009 
Table 1. Unit Cell and Magnetic Parameters of $\mathrm{Nd}_{18} \mathrm{Li}_{8} \mathrm{Fe}_{5-x} \mathrm{Mn}_{x} \mathrm{O}_{39}$

\begin{tabular}{|c|c|c|c|c|c|c|}
\hline$x$ & $a / \AA$ & $\theta / \mathrm{K}$ & $\begin{array}{c}C / \mathrm{cm}^{3} \\
\mathrm{~K} \mathrm{~mol}^{-1}\end{array}$ & $\begin{array}{c}C_{\text {calcd }} / \mathrm{cm}^{3} \\
\mathrm{~K} \mathrm{~mol}-1 a \\
\mathrm{Mn}^{3+} \mathrm{LS} / \mathrm{HS}\end{array}$ & $T_{\mathrm{f}} / \mathrm{K}$ & $\kappa$ \\
\hline $0^{2}$ & $11.96687(1)$ & $-28.0(2)$ & $43.67(4)$ & & 5.75 & 0.037 \\
\hline 1.0 & $11.9573(2)$ & $-25.9(2)$ & $47.02(6)$ & $45.80 / 47.24$ & $5.5(3)$ & 0.030 \\
\hline $2.5^{b}$ & $11.93852(6)$ & $-32.0(3)$ & $40.97(6)$ & $41.67 / 45.67$ & $5.5(3)$ & 0.021 \\
\hline 4.0 & $11.92461(9)$ & $-32.8(2)$ & $38.69(5)$ & $37.13 / 43.89$ & $4.75(25)$ & 0.017 \\
\hline
\end{tabular}

with the isomer shifts, quadrupole splittings, and line widths are $\pm 0.005, \pm 0.01$, and $\pm 0.01 \mathrm{~mm} / \mathrm{s}$, respectively; these errors are approximately twice as large for the trigonal-prismatic $16 i$ site. The absolute errors of these parameters are approximately twice the statistical errors.

\section{Results}

I. $\mathrm{Nd}_{18} \mathrm{Li}_{8} \mathrm{Fe}_{5-x} \mathrm{Mn}_{x} \mathrm{O}_{39}(\mathbf{1} \leq \boldsymbol{x} \leq 4)$. X-ray powder diffraction data indicated that compositions in this series having $x=1$ and 2.5 formed as highly crystalline, pure materials with the $\mathrm{La}_{18} \mathrm{Li}_{8} \mathrm{Rh}_{5} \mathrm{O}_{39}$ structure; all of the observed reflections could be indexed in the cubic space group $P m \overline{3} n$, with the unit cell parameters listed in Table 1. Small quantities of $\mathrm{Nd}_{2} \mathrm{O}_{3}$ (1.7(2) wt \%) and $\mathrm{Li}_{2} \mathrm{MnO}_{3}$ (1.9(2) wt $\%$ ) were detected along with the target phase in the sample having $x=4$. In all cases, the intensity distribution among the reflections from the principal phase was qualitatively consistent with the proposed structure. However, a full quantitative analysis could not be carried out, partly because of the dominant scattering factor of neodymium and partly because of the similarity in the scattering factors of the two transition metals; this was the case for all of the compounds discussed in this paper.

Neutron diffraction data were collected at room temperature on $\mathrm{Nd}_{18} \mathrm{Li}_{8} \mathrm{Fe}_{4} \mathrm{MnO}_{39}$ and $\mathrm{Nd}_{18} \mathrm{Li}_{8} \mathrm{FeMn}_{4} \mathrm{O}_{39}$. The former was again found to be monophasic, but an additional $\mathrm{Li}_{2} \mathrm{CO}_{3}$ impurity was detected (1.88(5) wt \%) in the latter. Both structures were refined in space group $P m \overline{3} n$ using the structure of $\mathrm{La}_{18} \mathrm{Li}_{8} \mathrm{Rh}_{5} \mathrm{O}_{39}$ as a starting model. There are two distinct $\mathrm{Nd}^{3+}$ sites in the asymmetric unit; the oxide ions $\mathrm{O} 2$ and $\mathrm{O} 3$ are coordinated exclusively to these cations. The oxide ion $\mathrm{O} 1$ forms the octahedron around the $8 e$ site at $(1 / 4,1 / 4,1 / 4)$, and $\mathrm{O} 4$ forms the octahedron around the $2 a$ site at $(0,0,0)$. $\mathrm{O} 1$ and $\mathrm{O} 4$ thus form the opposing triangular faces of the $16 i$ trigonal prismatic site. They also provide the link between the polyhedral chains and the $\mathrm{Nd}-\mathrm{O}$ framework. In the idealized structure, $\mathrm{O} 4$ would occupy the $12 f(x, 0,0)$ site, but in $\mathrm{La}_{18} \mathrm{Li}_{8} \mathrm{Rh}_{5} \mathrm{O}_{39}$, it is displaced onto the $48 l(x, y, z)$ site (with $25 \%$ occupancy). It was also necessary to introduce this disorder into the present data analysis. During the course of our refinements, we assumed that the $2 a$ site is too small to accommodate $\mathrm{Li}^{+}$. Furthermore, the Fe/Mn ratio determined for this site in preliminary analyses of both data sets resulted in a net scattering length of approximately zero. Consequently, in order to be able to refine the cation occupancy of this site, the mean atomic displacement parameter of the $2 a$ site was constrained to be
Table 2. Structural Parameters of $\mathrm{Nd}_{18} \mathrm{Li}_{8} \mathrm{Fe}_{4} \mathrm{MnO}_{39}$ and $\mathrm{Nd}_{18} \mathrm{Li}_{8} \mathrm{FeMn}_{4} \mathrm{O}_{39}$ at Room Temperature Refined from Neutron Diffraction Data: Space Group $P m \overline{3} n$

\begin{tabular}{|c|c|c|c|}
\hline & & $\mathrm{Nd}_{18} \mathrm{Li}_{8} \mathrm{Fe}_{4} \mathrm{MnO}_{39}$ & $\mathrm{Nd}_{18} \mathrm{Li}_{8} \mathrm{FeMn}_{4} \mathrm{O}_{39}$ \\
\hline$a / \AA ̊$ & & $11.95246(1)$ & $11.92633(1)$ \\
\hline $\mathrm{R}_{\mathrm{p}}, \chi^{2}$ & & $0.063,2.03$ & $0.057,1.96$ \\
\hline Nd1 $24 k$ & $y$ & $0.3073(3)$ & $0.3079(3)$ \\
\hline \multirow[t]{2}{*}{$0 y z$} & $z$ & $0.3051(3)$ & $0.3037(3)$ \\
\hline & $B_{\text {iso }} / \AA^{2}$ & $0.59(5)$ & $0.53(4)$ \\
\hline Nd2 $12 f$ & $x$ & $0.3475(3)$ & $0.3483(3)$ \\
\hline$x 00$ & $B_{\text {iso }} / \AA^{2}$ & $0.09(6)$ & $0.00(5)$ \\
\hline $\mathrm{Fe} 1(\mathrm{Mn}) 2 a$ & $B_{\text {iso }} / \AA^{2}$ & 0.00 & 0.00 \\
\hline \multirow[t]{2}{*}{000} & Fe occupancy & $0.72(1)$ & $0.38(1)$ \\
\hline & Mn occupancy & $0.28(1)$ & $0.62(1)$ \\
\hline $\mathrm{Fe} 2(\mathrm{Mn} / \mathrm{Li}) 8 e$ & $B_{\text {iso }} / \AA^{2}$ & $2.4(2)$ & $0.1913(3)$ \\
\hline \multirow[t]{3}{*}{$1 / 41 / 41 / 4$} & Fe occupancy & $0.67(1)$ & $0.156(1)$ \\
\hline & Mn occupancy & $0.180(3)$ & $0.844(1)$ \\
\hline & Li occupancy & $0.15(1)$ & 0.00 \\
\hline $\mathrm{Li}(\mathrm{Fe}) 16 i$ & $x$ & $0.373(1)$ & $0.3718(7)$ \\
\hline \multirow[t]{3}{*}{$x \times x$} & $B_{\text {iso }} / \AA^{2}$ & $0.1(4)$ & $0.17(3)$ \\
\hline & Li occupancy & $0.92(1)$ & 1.00 \\
\hline & Fe occupancy & $0.08(1)$ & 0.00 \\
\hline O1 $48 l$ & $x$ & $0.8642(3)$ & $0.8620(3)$ \\
\hline \multirow[t]{3}{*}{$x y z$} & $y$ & $0.8591(3)$ & $0.8589(3)$ \\
\hline & $z$ & $0.6940(2)$ & $0.6943(2)$ \\
\hline & $B_{\text {iso }} / \AA^{2}$ & $0.78(4)$ & $0.73(4)$ \\
\hline $\begin{array}{l}\mathrm{O} 26 d \\
1 / 41 / 20\end{array}$ & $B_{\text {iso }} / \AA^{2}$ & $1.1(2)$ & $0.83(2)$ \\
\hline O3 $12 g$ & $x$ & $0.6314(5)$ & $0.6319(5)$ \\
\hline$x 01 / 2$ & $B_{\text {iso }} / \AA^{2}$ & $0.68(10)$ & $0.65(9)$ \\
\hline O4 48l & $x$ & $0.1552(7)$ & $0.1547(6)$ \\
\hline \multirow[t]{4}{*}{$x y z$} & $y$ & $0.010(3)$ & $0.015(2)$ \\
\hline & $z$ & $-0.021(1)$ & $-0.013(2)$ \\
\hline & $B_{\text {iso }} / \AA^{2}$ & $1.9(3)$ & $1.6(3)$ \\
\hline & occupancy & 0.25 & 0.25 \\
\hline
\end{tabular}

zero for both compositions. In the case of $\mathrm{Nd}_{18} \mathrm{Li}_{8} \mathrm{Fe}_{4} \mathrm{MnO}_{39}$, the preliminary refinements also resulted in anomalously large displacement parameters at the $16 i$ and $8 e$ sites. These were reduced by varying the distribution of atoms with positive $(\mathrm{Fe})$ and negative $(\mathrm{Li}, \mathrm{Mn})$ neutron scattering lengths; the contrast between the neutron scattering lengths of iron and the other metals was crucial in the determination of the distribution of cations over the sites in the polyhedral chains. The best fit to the data came from a model in which iron is found in all three polyhedra, manganese in the two octahedra, and lithium in the trigonal prism and the larger of the two octahedra. The quantity of lithium transferred to the $8 e$ site matches the quantity of iron found in the $16 i$ sites, and the stoichiometry of the compound is thus maintained. In the case of $\mathrm{Nd}_{18} \mathrm{Li}_{8} \mathrm{FeMn}_{4} \mathrm{O}_{39}$, structural models in which iron and manganese partially occupied the prismatic site were again tested, but it was found that both of these metals occupy only the octahedral sites, and that lithium fully occupies the prismatic site. The relatively low value of the displacement parameter at the $8 e$ site in the composition $x$ $=4$ is consistent with the absence of the disorder that would accompany the introduction of relatively large $\mathrm{Li}^{+}$cations onto this site. The refined structural parameters for both the $x=1$ and 4 compositions are listed in Table 2, with the derived bond lengths in Table 3. The observed and calculated neutron diffraction profiles are shown in Figure 2.

The dc molar magnetic susceptibilities (defined as $\mathrm{M} / \mathrm{H}$ ) of compositions in the series $\mathrm{Nd}_{18} \mathrm{Li}_{8} \mathrm{Fe}_{5-x} \mathrm{M}_{x} \mathrm{O}_{39}(1 \leq x \leq$ 4) are shown in Figure 3; the susceptibility of $\mathrm{Nd}_{18} \mathrm{Li}_{8} \mathrm{Fe}_{5} \mathrm{O}_{39}$ is included for comparison. The results of fitting the data 
Table 3. Selected Bond Lengths ( $\AA$ ) and Angles (degrees) for $\mathrm{Nd}_{18} \mathrm{Li}_{8} \mathrm{Fe}_{4} \mathrm{MnO}_{39}$ and $\mathrm{Nd}_{18} \mathrm{Li}_{8} \mathrm{FeMn}_{4} \mathrm{O}_{39}$ at Room Temperature

\begin{tabular}{lcc}
\hline & $\mathrm{Nd}_{18} \mathrm{Li}_{8} \mathrm{Fe}_{4} \mathrm{MnO}_{39}$ & $\mathrm{Nd}_{18} \mathrm{Li}_{8} \mathrm{FeMn}_{4} \mathrm{O}_{39}$ \\
\hline $\mathrm{Nd} 1-\mathrm{O} 1$ & $2.498(4) \times 2$ & $2.495(5) \times 2$ \\
& $2.567(5) \times 2$ & $2.582(4) \times 2$ \\
$\mathrm{Nd} 1-\mathrm{O} 2$ & $2.632(4) \times 2$ & $2.596(4) \times 2$ \\
$\mathrm{Nd} 1-\mathrm{O} 3$ & $2.428(4)$ & $2.421(4)$ \\
& $2.425(4)$ & $2.416(4)$ \\
$\mathrm{Nd} 2-\mathrm{O} 1$ & $3.102(4)$ & $3.074(4)$ \\
$\mathrm{Nd} 2-\mathrm{O} 3$ & $2.394(3) \times 4$ & $2.408(3) \times 4$ \\
$\mathrm{Nd} 2-\mathrm{O} 4$ & $2.405(5) \times 2$ & $2.397(5) \times 2$ \\
$\mathrm{Fe} 1(\mathrm{Mn})-\mathrm{O} 4$ & $2.303(9)$ & $2.321(8)$ \\
$\mathrm{Fe} 2(\mathrm{Mn} / \mathrm{Li})-\mathrm{O} 1$ & $1.88(5) \times 6$ & $1.86(2) \times 6$ \\
$\mathrm{Li}(\mathrm{Fe})-\mathrm{O} 1$ & $2.001(3) \times 6$ & $1.978(3) \times 6$ \\
$\mathrm{Li}(\mathrm{Fe})-\mathrm{O} 4$ & $2.146(14) \times 3$ & $2.126(9) \times 3$ \\
$\mathrm{Li}(\mathrm{Fe})-\mathrm{Li}(\mathrm{Fe})$ & $2.19(3)^{a} \times 3$ & $2.19(2)^{a} \times 3$ \\
$\mathrm{Fe} 1(\mathrm{Mn})-\mathrm{Li}(\mathrm{Fe})$ & $3.046(17)$ & $3.058(12)$ \\
$\mathrm{Fe} 2(\mathrm{Mn})-\mathrm{Li}(\mathrm{Fe})$ & $2.637(13)$ & $2.648(8)$ \\
$\mathrm{O} 1-\mathrm{Fe} 2(\mathrm{Mn} / \mathrm{Li})-\mathrm{O} 1$ & $2.538(13)$ & $2.516(8)$ \\
& $90.1(2)$ & $90.2(2)$ \\
& $88.2(2)$ & $88.7(2)$ \\
& $91.7(2)$ & $90.9(2)$
\end{tabular}

${ }^{a}$ Denotes an average of bonds to a disordered oxygen position.
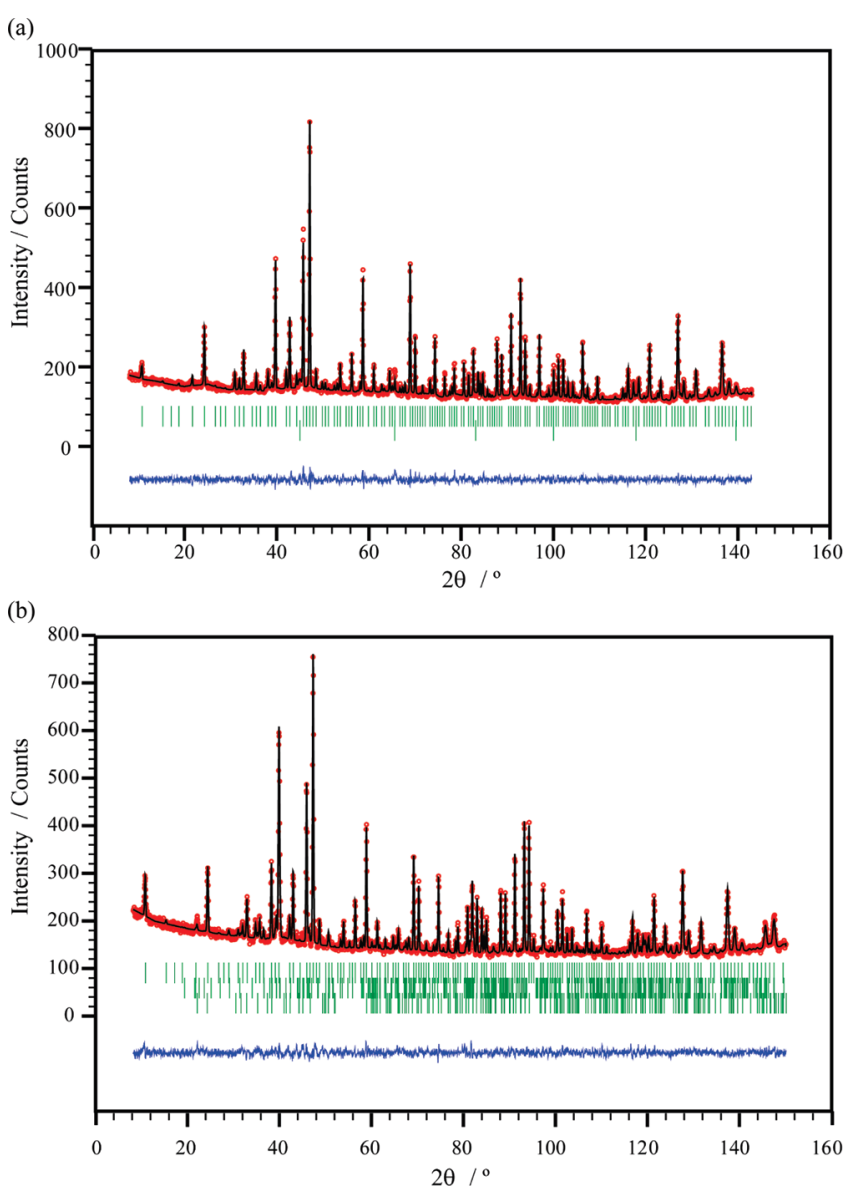

Figure 2. Observed, calculated, and difference neutron powder diffraction patterns of (a) $\mathrm{Nd}_{18} \mathrm{Li}_{8} \mathrm{Fe}_{4} \mathrm{MnO}_{39}$ and (b) $\mathrm{Nd}_{18} \mathrm{Li}_{8} \mathrm{FeMn}_{4} \mathrm{O}_{39}$ at room temperature. Vertical bars mark reflection positions for, in descending order, (a) the principal phase and the vanadium sample container and (b) the principal phase, $\mathrm{Li}_{2} \mathrm{MnO}_{3}$ and $\mathrm{Li}_{2} \mathrm{CO}_{3}$.

collected above $100 \mathrm{~K}$ to a Curie-Weiss law are given in Table 1. All samples show a negative Weiss temperature $(\theta)$ and a susceptibility maximum at $T_{\mathrm{f}} \sim 5 \mathrm{~K}$ (Table 1 ). Below $T_{\mathrm{f}}$, the susceptibility measured under FC conditions is greater than that measured under ZFC conditions. The field dependence of the magnetization at $2 \mathrm{~K}$ after cooling in a

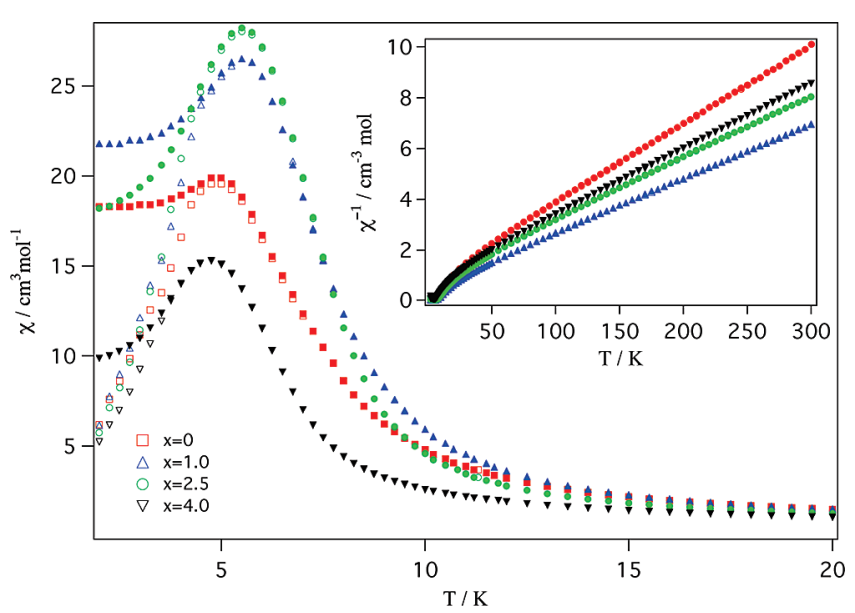

Figure 3. Temperature dependence of the dc molar magnetic susceptibility of $\mathrm{Nd}_{18} \mathrm{Li}_{8} \mathrm{Fe}_{5-x} \mathrm{Mn}_{x} \mathrm{O}_{39}$; solid and hollow symbols represent FC and ZFC data, respectively. The inverse susceptibility is inset.

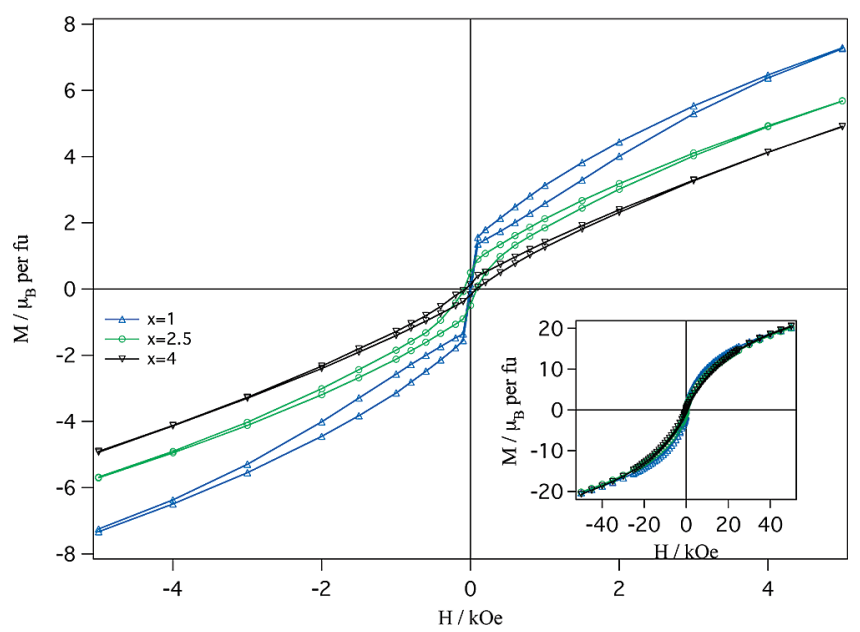

Figure 4. Field dependence of the magnetization per formula unit at $2 \mathrm{~K}$ for compositions in the system $\mathrm{Nd}_{18} \mathrm{Li}_{8} \mathrm{Fe}_{5-x} \mathrm{Mn}_{x} \mathrm{O}_{39}$.

field of $50 \mathrm{kOe}$ is shown in Figure 4; in each case, $\mathrm{M}(\mathrm{H})$ is nonlinear and hysteresis is apparent around the origin. The ac magnetic susceptibilities of compositions $x=1$ and $x=$ 4 are shown in Figures 5 and 6, respectively. In each case, $\chi^{\prime}$ becomes frequency-dependent below $\sim 7.5 \mathrm{~K}$, and the temperature of the maximum in $\chi^{\prime}$ is frequency-dependent. The ratio of the change in $T_{\mathrm{f}}$ to the decadic shift in frequency $\left(\kappa=\Delta T_{\mathrm{f}} / T_{\mathrm{f}} \Delta \log \omega\right)$ is greater in the case of $x=1(0.030)$ than in that of $x=4(0.017)$. The imaginary component of the susceptibility is nonzero for both compositions below $\sim 7.5 \mathrm{~K}$, and for $x=1$, the maximum in $\chi^{\prime}$ corresponds to the minimum temperature gradient of $\chi^{\prime}$ for all frequencies (Figure S1, Supporting Information). However, when $x=$ 4 , this gradient shows two local minima, one on either side of $T_{\mathrm{f}}$; this effect is more obvious at low frequencies (Figure S2, Supporting Information). The ac susceptibility of $\mathrm{Nd}_{18} \mathrm{Li}_{8} \mathrm{Fe}_{2.5} \mathrm{Mn}_{2.5} \mathrm{O}_{39}$ is shown in Figure $\mathrm{S} 3$ (Supporting Information); $\mathrm{d} \chi^{\prime \prime} / \mathrm{d} T$ shows a single minimum coincident with $T_{\mathrm{f}}$ and $\kappa=0.021$.

Neutron diffraction data collected on $\mathrm{Nd}_{18} \mathrm{Li}_{8} \mathrm{Fe}_{4} \mathrm{MnO}_{39}$ at $3.3 \mathrm{~K} \mathrm{did} \mathrm{not} \mathrm{show} \mathrm{any} \mathrm{reflections} \mathrm{that} \mathrm{were} \mathrm{not} \mathrm{observed}$ at room temperature, nor were any significant intensity differences apparent between the two data sets. The low- 

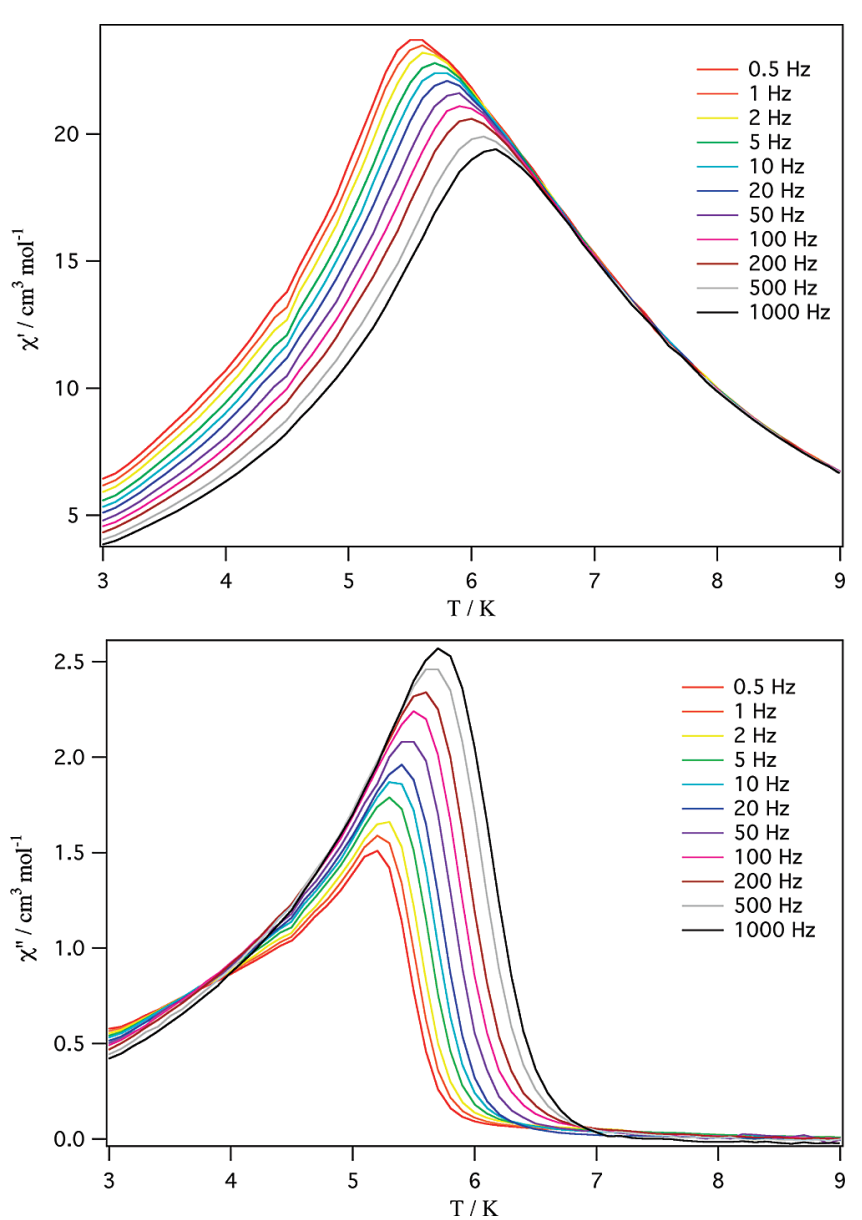

Figure 5. Temperature and frequency dependence of the real (upper) and imaginary (lower) components of the ac molar susceptibility of $\mathrm{Nd}_{18} \mathrm{Li}_{8} \mathrm{Fe}_{4} \mathrm{MnO}_{39}$.

temperature data were therefore analyzed using the structural model described above; the resulting structural parameters are listed in Table 4 . The cation distribution resulting from these refinements is the same, within error, as that described in Table 2. During the course of these calculations, the displacement parameter of $\mathrm{Nd} 2$ refined to a value of $-0.09(5)$ $\AA^{2}$; it was subsequently set to zero and not refined. The observed and calculated $3.3 \mathrm{~K}$ diffraction profiles are shown in Figure S4 (Supporting Information).

The iron-57 Mössbauer spectra of $\mathrm{Nd}_{18} \mathrm{Li}_{8} \mathrm{Fe}_{4} \mathrm{MnO}_{39}$ have been measured between 4.2 and $295 \mathrm{~K}$. The spectra indicate that $\mathrm{Nd}_{18} \mathrm{Li}_{8} \mathrm{Fe}_{4} \mathrm{MnO}_{39}$ is paramagnetic from 295 to $50 \mathrm{~K}$, just begins to exhibit a weak magnetic sextet at $25 \mathrm{~K}$, and exhibits three fully resolved magnetic sextets at $4.2 \mathrm{~K}$, see Figures 7 and 8.

The paramagnetic spectra obtained at and above $25 \mathrm{~K}$ have been fit with three doublets assigned to the $2 a, 8 e$, and $16 i$ sites, with relative areas constrained to $18.00,66.73$, and $15.27 \%$, respectively; the iron occupancy of these sites was determined at room temperature by neutron diffraction and is given in Table 2. The resulting fits, see Figure 7, and the corresponding spectral parameters, see Table S1 (Supporting Information) and Figures 9 and 10, are most consistent with the electronic properties of $\mathrm{Nd}_{18} \mathrm{Li}_{8} \mathrm{Fe}_{4} \mathrm{MnO}_{39}$, which formally contains iron(III) ions on the $8 e$ and $16 i$ crystallographic sites and iron(IV) ions on the $2 a$ site.
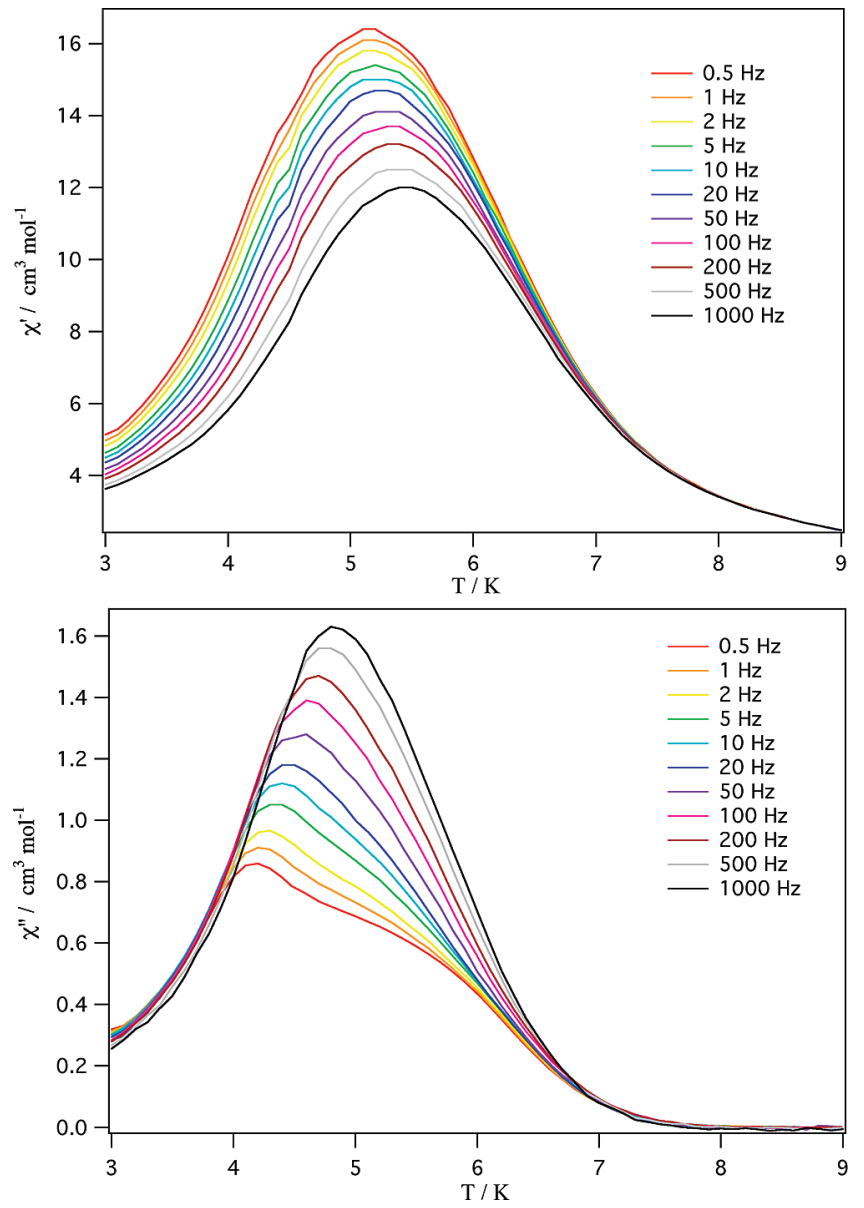

Figure 6. Temperature and frequency dependence of the real (upper) and imaginary (lower) components of the ac molar susceptibility of $\mathrm{Nd}_{18} \mathrm{Li}_{8} \mathrm{FeMn}_{4} \mathrm{O}_{39}$.

The $25 \mathrm{~K}$ Mössbauer spectrum of $\mathrm{Nd}_{18} \mathrm{Li}_{8} \mathrm{Fe}_{4} \mathrm{MnO}_{39}$ has been measured at both \pm 3 and $\pm 12 \mathrm{~mm} / \mathrm{s}$, and in addition to the paramagnetic components observed at $\pm 3 \mathrm{~mm} / \mathrm{s}$, the $\pm 12 \mathrm{~mm} / \mathrm{s}$ spectrum indicates the presence, $\mathrm{ca}$. $20 \%$ by area, of a magnetic sextet with a hyperfine field of $\sim 45 \mathrm{~T}$ and an isomer shift of $\sim 0.44 \mathrm{~mm} / \mathrm{s}$, parameters that are characteristic of iron(III). However, the paramagnetic components have been fit with the same relative areas and hyperfine parameters as observed at $25 \mathrm{~K}$ and $\pm 3 \mathrm{~mm} / \mathrm{s}$.

The $4.2 \mathrm{~K}$ spectrum of $\mathrm{Nd}_{18} \mathrm{Li}_{8} \mathrm{Fe}_{4} \mathrm{MnO}_{39}$ has been fit with the superposition of three sextets, with hyperfine fields of 20.0(5), 51.2(2), and 47(1) T, assigned to the $2 a, 8 e$, and $16 i$ sites, respectively, with the relative areas constrained to the iron occupancy of these sites determined by neutron diffraction and given above. The remaining spectral parameters of these sextets are given in Table S1 (Supporting Information). Both isomer shifts and hyperfine fields ${ }^{6}$ are compatible with the presence of low-spin iron(IV) on the $2 a$ site and high-spin iron(III) on the $8 e$ and $16 i$ sites.

Confidence in the model used for the Mössbauer spectral fits described above may be obtained through the temperature dependence of the isomer shifts and quadrupole splittings observed for the $2 a, 8 e$, and $16 i$ sites and their weighted

(6) Russo, U.; Long, G. J. In Mössbauer Spectroscopy Applied to Inorganic Chemistry, Long, G. J., Grandjean, F., Eds.; Plenum Press: New York, 1989; Vol. 3, p 289. 
Table 4. Structural Parameters of $\mathrm{Nd}_{18} \mathrm{Li}_{8} \mathrm{Fe}_{4} \mathrm{MnO}_{39}$ at $3.3 \mathrm{~K}$ Refined from Neutron Diffraction Data: Space Group $P m \overline{3} n$

$\begin{array}{lll}a / \AA & & 11.92761(1) \\ R_{\mathrm{p}}, \chi^{2} & & 0.060,3.80 \\ \mathrm{Nd} 124 k & z & 0.3075(3) \\ 0 y z & B_{\text {iso }} / \AA^{2} & 0.3054(3) \\ & x & 0.27(4) \\ \mathrm{Nd} 212 f & B_{\text {iso }} / \AA^{2} & 0.3489(3) \\ x 00 & B_{\text {iso }} / \AA^{2} & 0.00 \\ \mathrm{Fe} 1(\mathrm{Mn}) 2 a & \mathrm{Fe} \text { occupancy } & 0.5(3) \\ 000 & \mathrm{Mn} \text { occupancy } & 0.72(2) \\ & B_{\text {iso }} / \AA^{2} & 0.28(2) \\ \mathrm{Fe} 2(\mathrm{Mn} / \mathrm{Li}) 8 e & \mathrm{Fe} \text { occupancy } & 2.2(2) \\ 1 / 41 / 41 / 4 & \mathrm{Mn} \text { occupancy } & 0.67(1) \\ & \mathrm{Li} \text { occupancy } & 0.181(4) \\ \mathrm{Li}(\mathrm{Fe}) 16 i & x & 0.15(1) \\ x x x & B_{\text {iso }} / \AA^{2} & 0.3705(9) \\ & \mathrm{Li} \text { occupancy } & 0.5(4) \\ \mathrm{O} 148 l & \mathrm{Fe} \text { occupancy } & 0.93(1) \\ x y z & x & 0.07(1) \\ & y & 0.8642(3) \\ \mathrm{O} 26 d & z & 0.8592(3) \\ 1 / 41 / 20 & B_{\text {iso }} / \AA^{2} & 0.6934(2) \\ \mathrm{O} 312 g & B_{\text {iso }} / \AA^{2} & 0.45(4) \\ x 01 / 2 & x & 0.56(1) \\ \mathrm{O} 448 l & x & \\ x y z & B_{\text {iso }} / \AA^{2} & 0.6317(4) \\ & x & 0.42(8) \\ & y & 0.1557(6) \\ & z & 0.011(2) \\ & B_{\text {iso }} / \AA^{2} & 0.017(2) \\ \text { occupancy } & 0.1(3) \\ & & \end{array}$

average values, see Figures 9 and 10, respectively. As expected, the three isomer shifts decrease with increasing temperature because of the second-order Doppler shift. ${ }^{7}$ A fit with the Debye model yields the solid line fits shown in Figure 9 and Debye temperatures of 850(100), 450(70), $578(25)$, and $518(55) \mathrm{K}$ for the $2 a, 8 e$, and $16 i$ site isomer shifts and their weighted average, respectively. The higher value for the $2 a$ site results because this is the iron(IV) site with shorter bonds and the corresponding higher vibrational frequencies.

Between 25 and $295 \mathrm{~K}$, the quadrupole splittings of the $2 a, 8 e$, and $16 i$ sites are virtually constant. Consequently, in fitting the $4.2 \mathrm{~K}$ spectrum, see Figure 8 , the values of the quadrupole splitting have been constrained to the values given in Table S1 (Supporting Information), and the values of $\theta$, the angle between the principal axis of the electric field gradient and the magnetic hyperfine field, have been adjusted, yielding $20(1), 45.8(5)$, and $53(1)^{\circ}$ for the $2 a, 8 e$, and $16 i$ sites, respectively. These $\theta$ values lead to virtually zero quadrupole shifts and nearly symmetric sextets for the $8 e$ and $16 i$ sites and to a positive quadrupole shift for the $2 a$ site, a shift that is clearly visible for the green component in Figure 8 . The $4.2 \mathrm{~K}$ line widths are $0.45(1), 0.53(1)$, and $0.55(1) \mathrm{mm} / \mathrm{s}$ for the $2 a, 8 e$, and $16 i$ sites, respectively. These values represent a significant broadening as compared with both the line widths observed above $25 \mathrm{~K}$ and the instrumental line width of $0.25(1) \mathrm{mm} / \mathrm{s}$.

The Mössbauer spectrum of $\mathrm{Nd}_{18} \mathrm{Li}_{8} \mathrm{FeMn}_{4} \mathrm{O}_{39}$ has been obtained at $25 \mathrm{~K}$, see Figure 11, and fit with two symmetric

(7) Shenoy, G. K.; Wagner, F. E.; Kalvius, G. M. In Mössbauer Isomer Shifts; Shenoy, G. K., Wagner, F. E., Eds.; North-Holland: Amsterdam, 1978; p 49.

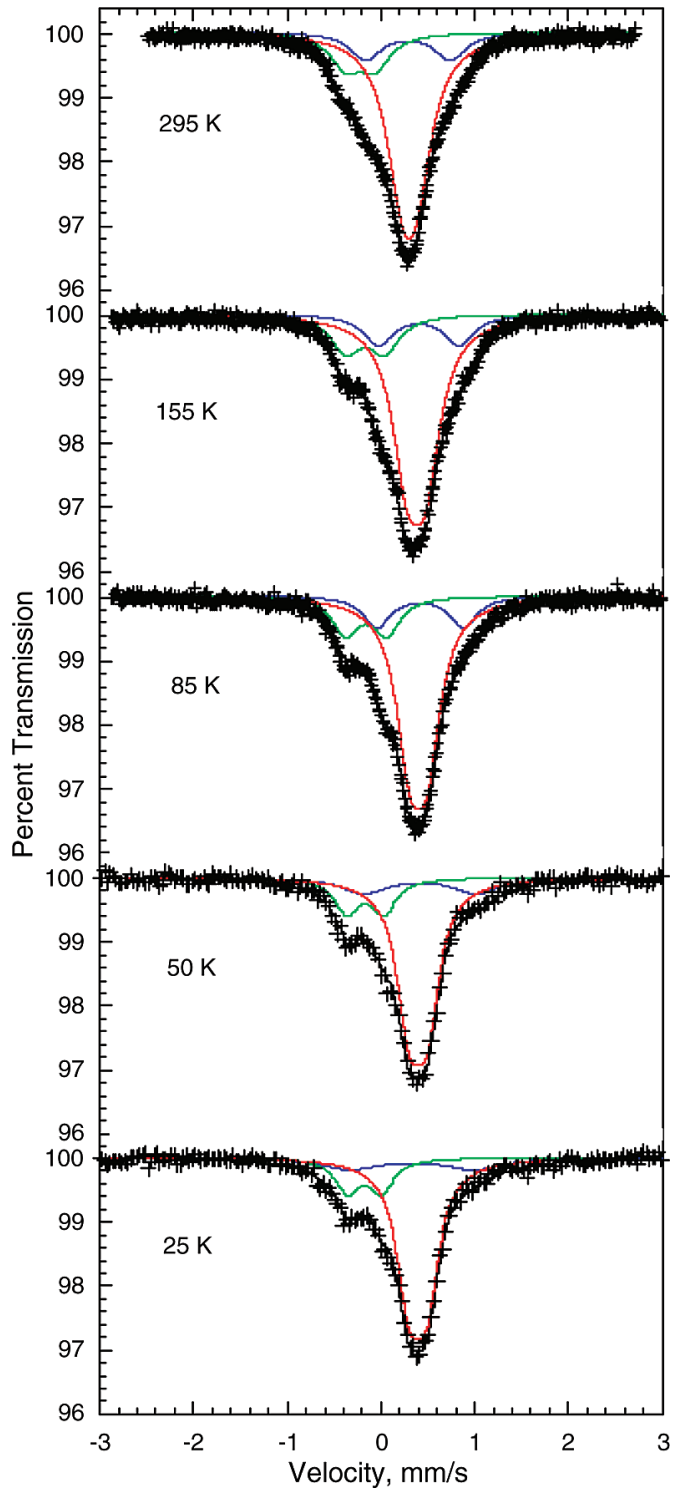

Figure 7. The iron-57 Mössbauer spectra of $\mathrm{Nd}_{18} \mathrm{Li}_{8} \mathrm{Fe}_{4} \mathrm{MnO}_{39}$ measured at the indicated temperatures. The green, red, and blue lines correspond to the components assigned to the $2 a, 8 e$, and $16 i$ sites, respectively.

quadrupole doublets with relative areas of 38 and $62 \%$ for the $2 a$ and $8 e$ sites, respectively; the iron occupancy of these sites was determined at room temperature by neutron diffraction, see Table 2. No iron is observed on the $16 i$ site in this compound. The hyperfine parameters of the $2 a$ and $8 e$ sites, see Table S1 (Supporting Information), resemble those of $\mathrm{Nd}_{18} \mathrm{Li}_{8} \mathrm{Fe}_{4} \mathrm{MnO}_{39}$ at $25 \mathrm{~K}$, but the isomer shifts are slightly smaller because of the presence of the additional manganese in place of iron. Thus, $\mathrm{Nd}_{18} \mathrm{Li}_{8} \mathrm{FeMn}_{4} \mathrm{O}_{39}$ also contains low-spin iron(IV) on the $2 a$ site and high-spin iron(III) on the $8 e$ site. No further spectra have been obtained because of the extensive nonresonant scattering by the neodymium and the small amount of iron present.

II. $\mathrm{Nd}_{18} \mathrm{Li}_{8} \mathrm{Fe}_{5-x} \mathrm{Co}_{x} \mathrm{O}_{39}(1 \leq x \leq 4)$. X-ray powder diffraction data indicated that highly crystalline, single-phase samples of $\mathrm{Nd}_{18} \mathrm{Li}_{8} \mathrm{Fe}_{5-x} \mathrm{Co}_{x} \mathrm{O}_{39}$ could be prepared for $1 \leq x$ $\leq 3$; our sample of $\mathrm{Nd}_{18} \mathrm{Li}_{8} \mathrm{FeCo}_{4} \mathrm{O}_{39}$ contained a trace (1.2(2) wt \%) of $\mathrm{LiCoO}_{2}$ and was therefore not analyzed in detail. 


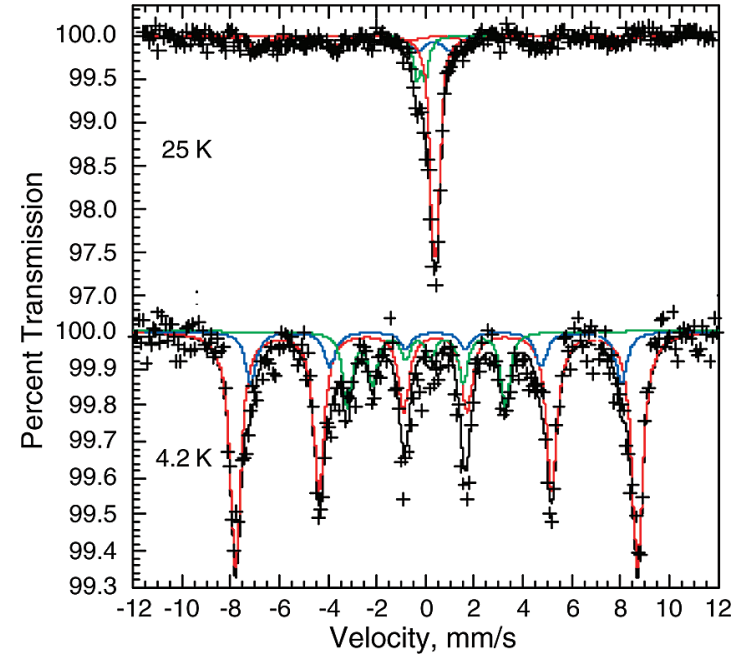

Figure 8. The iron-57 Mössbauer spectra of $\mathrm{Nd}_{18} \mathrm{Li}_{8} \mathrm{Fe}_{4} \mathrm{MnO}_{39}$ obtained at 25 and $4.2 \mathrm{~K}$. The green, red, and blue lines correspond to the components assigned to the $2 a, 8 e$, and $16 i$ sites, respectively.

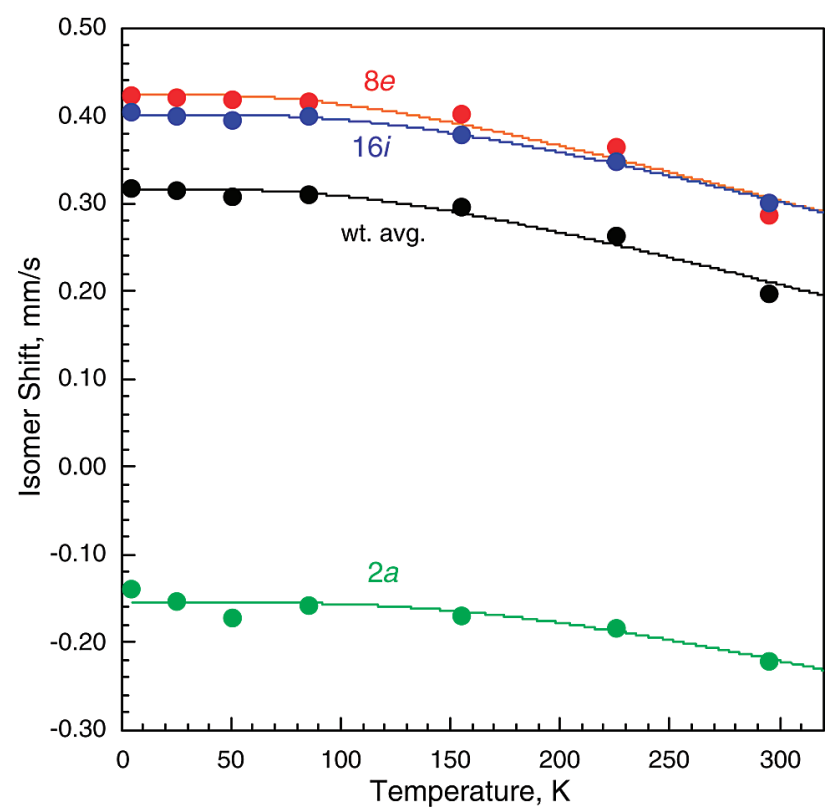

Figure 9. The temperature dependence of the Mössbauer isomer shifts for the $2 a, 8 e$, and $16 i$ sites, and their weighted average, in $\mathrm{Nd}_{18} \mathrm{Li}_{8} \mathrm{Fe}_{4} \mathrm{MnO}_{39}$. The solid lines correspond to a fit with the Debye model for a solid. The error bars are at most the size of the data points.

The diffraction pattern from each sample could be accounted for in space group $P m \overline{3} n$ with a unit-cell parameter that decreased with increasing cobalt content (Table 5).

Neutron diffraction data were collected at room temperature on $\mathrm{Nd}_{18} \mathrm{Li}_{8} \mathrm{Fe}_{4} \mathrm{CoO}_{39}$. They revealed a $\mathrm{Li}_{2} \mathrm{CO}_{3}$ impurity (2.3(1) wt \%) that had not been detected by $\mathrm{X}$-ray diffraction. The structure of $\mathrm{La}_{18} \mathrm{Li}_{8} \mathrm{Rh}_{5} \mathrm{O}_{39}$ was again used as the starting point in our data analysis. Preliminary refinements of the cation distribution over the octahedral sites showed that the $2 a$ site at $(0,0,0)$ is fully occupied by iron, and the occupancy of this site was therefore held constant in subsequent refinements. The initial refinements resulted in unusually large displacement parameters at the $8 e$ octahedral and $16 i$ prismatic sites, and the distribution of cations over these sites was refined. Allowance was made for the possibility of a substoichiometric lithium content. The best

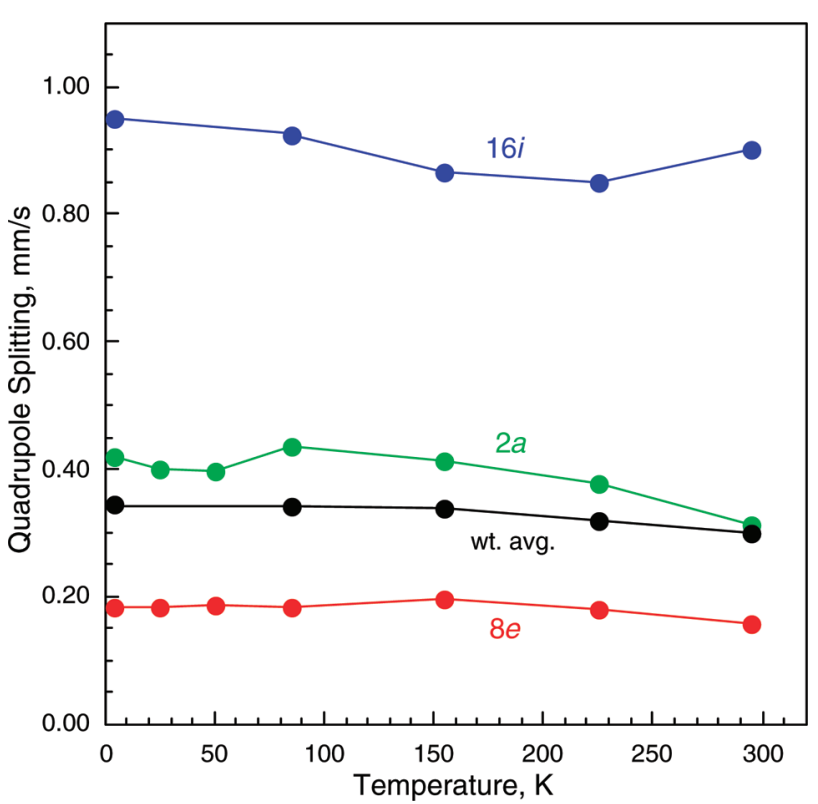

Figure 10. The temperature dependence of the Mössbauer quadrupole splittings for the $2 a, 8 e$, and $16 i$ sites, and their weighted average, in $\mathrm{Nd}_{18} \mathrm{Li}_{8} \mathrm{Fe}_{4} \mathrm{MnO}_{39}$. The error bars are at most twice the size of the data points.

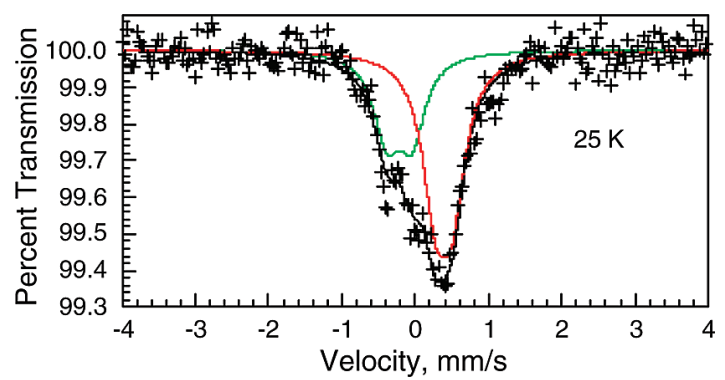

Figure 11. The iron-57 Mössbauer spectra of $\mathrm{Nd}_{18} \mathrm{Li}_{8} \mathrm{FeMn}_{4} \mathrm{O}_{39}$ measured at $25 \mathrm{~K}$. The green and red lines correspond to the components assigned to the $2 a$ and $8 e$ sites, respectively.

Table 5. Unit Cell and Magnetic Parameters of $\mathrm{Nd}_{18} \mathrm{Li}_{8} \mathrm{Fe}_{5-x} \mathrm{Co}_{x} \mathrm{O}_{39}$

\begin{tabular}{|c|c|c|c|c|c|c|}
\hline$x$ & $a / \AA ̊$ & $\theta / \mathrm{K}$ & $\begin{array}{c}C / \mathrm{cm}^{3} \\
\mathrm{~K} \mathrm{~mol}{ }^{-1}\end{array}$ & $\begin{array}{l}C_{\text {calcd }} / \mathrm{cm}^{3} \\
\mathrm{~K} \mathrm{~mol}^{-1 a}\end{array}$ & $T_{\mathrm{f}} / \mathrm{K}$ & $\kappa$ \\
\hline 1 & $11.93617(6)$ & $-31.2(3)$ & $43.56(7)$ & 43.61 & $4.5(3)$ & 0.043 \\
\hline 2 & $11.90336(6)$ & $-33.5(2)$ & $39.01(5)$ & $39.24(40.75)$ & $3.5(3)$ & 0.064 \\
\hline 3 & $11.87478(5)$ & $-36.9(3)$ & $36.46(6)$ & $34.86(37.13)$ & $2.3(1)$ & 0.046 \\
\hline
\end{tabular}

fit to the data was achieved when the stoichiometry of the composition was maintained. In our final model, the $16 i$ sites are both occupied by a disordered distribution of lithium and iron, whereas the $8 e$ sites accommodate all of the cobalt and the remainder of the lithium and iron. The atom $\mathrm{O} 4$ is disordered, as it was in the manganese analogue. Details of this model are given in Table 6, and the most important bond lengths are listed in Table 7. The observed and calculated neutron diffraction patterns are shown in Figure S5 (Supporting Information).

Both the ZFC and FC magnetic susceptibilities of $\mathrm{Nd}_{18} \mathrm{Li}_{8} \mathrm{Fe}_{4} \mathrm{CoO}_{39}$ show a maximum at $T_{\mathrm{f}}=4.5(3) \mathrm{K}$. Below 
Table 6. Structural Parameters of $\mathrm{Nd}_{18} \mathrm{Li}_{8} \mathrm{Fe}_{4} \mathrm{CoO}_{39}$ at Room Temperature Refined from Neutron Diffraction Data: Space Group Pm $\overline{3} n$

\begin{tabular}{|c|c|c|}
\hline$a / \AA ̊$ & & $11.93146(1)$ \\
\hline$R_{\mathrm{p}}, \chi^{2}$ & & $0.052,2.02$ \\
\hline Nd1 $24 k$ & $y$ & $0.3073(3)$ \\
\hline \multirow[t]{2}{*}{$0 y z$} & $z$ & $0.3047(3)$ \\
\hline & $B_{\text {iso }} / \AA^{2}$ & $0.50(4)$ \\
\hline $\mathrm{Nd} 212 f$ & $x$ & $0.3482(3)$ \\
\hline$x 00$ & $B_{\text {iso }} / \AA^{2}$ & $0.07(5)$ \\
\hline $\mathrm{Fe} 12 a$ & $B_{\text {iso }} / \AA^{2}$ & $0.5(1)$ \\
\hline \multicolumn{3}{|l|}{000} \\
\hline $\mathrm{Fe} 2(\mathrm{Co} / \mathrm{Li}) 8 e$ & $B_{\text {iso }} / \AA^{2}$ & $1.8(1)$ \\
\hline \multirow[t]{3}{*}{$1 / 4 \quad 1 / 4 \quad 1 / 4$} & Fe occupancy & $0.65(1)$ \\
\hline & Co occupancy & 0.25 \\
\hline & Li occupancy & $0.10(1)$ \\
\hline $\mathrm{Li}(\mathrm{Fe}) 16 i$ & $x$ & $0.3689(7)$ \\
\hline \multirow[t]{3}{*}{$x \times x$} & $\mathrm{~B}_{\text {iso }} / \AA^{2}$ & $0.1(3)$ \\
\hline & Fe occupancy & $0.050(5)$ \\
\hline & Li occupancy & $0.950(5)$ \\
\hline O1 $48 l$ & $x$ & $0.8644(3)$ \\
\hline \multirow[t]{3}{*}{$x y z$} & $y$ & $0.8593(3)$ \\
\hline & $z$ & $0.6942(2)$ \\
\hline & $B_{\text {iso }} / \AA^{2}$ & $0.74(4)$ \\
\hline $\mathrm{O} 26 d$ & $B_{\text {isoo }} / \AA^{2}$ & $0.7(1)$ \\
\hline \multicolumn{3}{|l|}{$1 / 41 / 20$} \\
\hline O3 $12 g$ & $x$ & $0.6316(5)$ \\
\hline $\begin{array}{lll}x & 0 & 1 / 2\end{array}$ & $B_{\text {iso }} / \AA^{2}$ & $0.60(9)$ \\
\hline O4 48l & $x$ & $0.1532(7)$ \\
\hline \multirow[t]{4}{*}{$x y z$} & $y$ & $0.016(2)$ \\
\hline & $z$ & $-0.019(2)$ \\
\hline & $B_{\text {iso }} / \AA^{2}$ & $2.5(3)$ \\
\hline & occupancy & 0.25 \\
\hline
\end{tabular}

Table 7. Selected bond lengths $(\AA)$ and angles (degrees) for $\mathrm{Nd}_{18} \mathrm{Li}_{8} \mathrm{Fe}_{4} \mathrm{CoO}_{39}$ at room temperature

$\begin{array}{ll}\mathrm{Nd} 1-\mathrm{O} 1 & 2.563(5) \times 2 \\ & 2.503(4) \times 2 \\ & 2.625(4) \times 2 \\ \mathrm{Nd} 1-\mathrm{O} 2 & 2.386(4) \\ \mathrm{Nd} 1-\mathrm{O} 3 & 2.422(4) \\ & 3.091(4) \\ \mathrm{Nd} 2-\mathrm{O} 1 & 2.386(3) \times 4 \\ \mathrm{Nd} 2-\mathrm{O} 3 & 2.397(5) \times 2 \\ \mathrm{Nd} 2-\mathrm{O} 4 & 2.345(9) \\ \mathrm{Fe} 1-\mathrm{O} 4 & 1.85(2) \times 6 \\ \mathrm{Fe} 2(\mathrm{Co} / \mathrm{Li})-\mathrm{O} 1 & 2.002(3) \times 6 \\ \mathrm{Li}(\mathrm{Fe})-\mathrm{O} 1 & 2.088(9) \times 3 \\ \mathrm{Li}(\mathrm{Fe})-\mathrm{O} 4 & 2.238(2)^{a} \times 3 \\ \mathrm{Li}(\mathrm{Fe})-\mathrm{Li}(\mathrm{Fe}) & 3.128(12) \\ \mathrm{Fe} 1-\mathrm{Li}(\mathrm{Fe}) & 2.709(8) \\ \mathrm{Fe} 2(\mathrm{Co} / \mathrm{Li})-\mathrm{Li}(\mathrm{Fe}) & 2.457(8) \\ \mathrm{O} 1-\mathrm{Fe} 2(\mathrm{Co} / \mathrm{Li})-\mathrm{O} 1 & 89.9(2) \\ & 88.3(2) \\ & 91.8(2)\end{array}$

${ }^{a}$ Denotes an average of bonds to a disordered oxygen position.

this temperature, the FC susceptibility becomes independent of temperature, whereas the ZFC susceptibility decreases with decreasing temperature (Figure 12). Above $100 \mathrm{~K}$, the inverse susceptibility is a linear function of temperature that can be modeled using the Curie-Weiss law (Table 5). As can be seen from Figure 12 and Table 5, the more cobalt-rich samples show qualitatively similar behavior, although the value of $T_{\mathrm{f}}$ decreases with cobalt content. At $2 \mathrm{~K}$, hysteresis is apparent in the field dependence of the magnetization for fields of less than $10 \mathrm{kOe}$ (Figure 13); the width of the hysteresis loops decreases as the cobalt content of the sample increases. In no case does the magnetization saturate in a field of $50 \mathrm{kOe}$. The ac susceptibility of $\mathrm{Nd}_{18} \mathrm{Li}_{8} \mathrm{Fe}_{4} \mathrm{CoO}_{39}$ is shown in Figure S6 (Supporting Information). The real component becomes frequency dependent below $\sim 6 \mathrm{~K}$, and

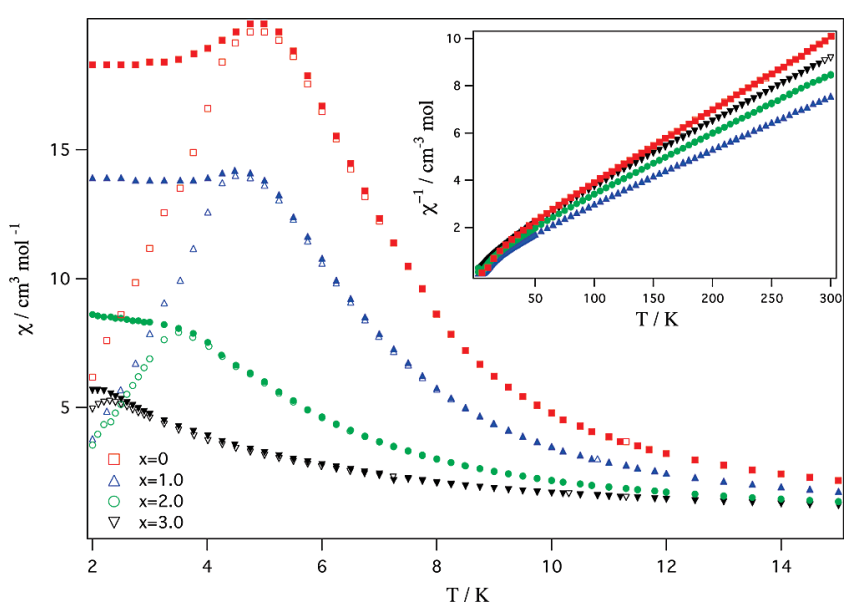

Figure 12. Temperature dependence of the dc molar magnetic susceptibility of $\mathrm{Nd}_{18} \mathrm{Li}_{8} \mathrm{Fe}_{5-x} \mathrm{Co}_{x} \mathrm{O}_{39}$. Solid and hollow symbols represent FC and ZFC data, respectively. The inverse susceptibility is inset.

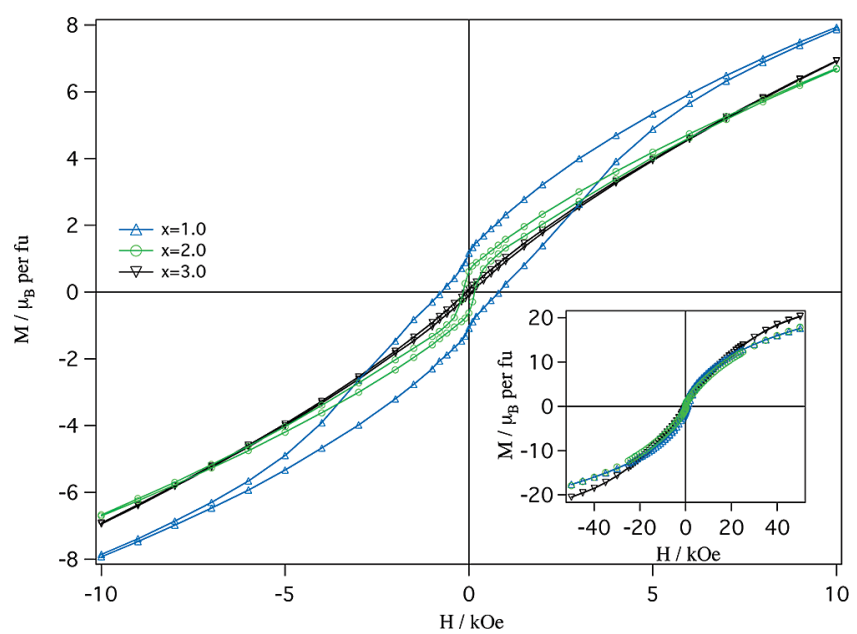

Figure 13. Field dependence of the magnetization per formula unit at $2 \mathrm{~K}$ for compositions in the system $\mathrm{Nd}_{18} \mathrm{Li}_{8} \mathrm{Fe}_{5-x} \mathrm{Co}_{x} \mathrm{O}_{39}$.

the imaginary component becomes nonzero at the same temperature. Only one maximum is observed in $\chi^{\prime}$. Figures S7 and S8 (Supporting Information) show that all of the $\mathrm{Nd}_{18} \mathrm{Li}_{8} \mathrm{Fe}_{5-x} \mathrm{Co}_{x} \mathrm{O}_{39}$ compositions behave in a similar manner. The value of the parameter $\kappa$ for each composition is included in Table 5.

The iron-57 Mössbauer spectra of $\mathrm{Nd}_{18} \mathrm{Li}_{8} \mathrm{Fe}_{4} \mathrm{CoO}_{39}$ have been measured between 4.2 and $295 \mathrm{~K}$. The spectra indicate that $\mathrm{Nd}_{18} \mathrm{Li}_{8} \mathrm{Fe}_{4} \mathrm{CoO}_{39}$ is paramagnetic at $295 \mathrm{~K}$ to just above $25 \mathrm{~K}$ and exhibits three fully resolved magnetic sextets at $4.2 \mathrm{~K}$, see Figures S9 and S10 (Supporting Information); the appearances of these spectra are very similar to those of $\mathrm{Nd}_{18} \mathrm{Li}_{8} \mathrm{Fe}_{4} \mathrm{MnO}_{39}$ discussed above.

The paramagnetic spectra obtained at and above $25 \mathrm{~K}$ have been fit with three doublets assigned to the $2 a, 8 e$, and $16 i$ sites, with relative areas constrained to 25,65 , and $10 \%$, respectively; the iron occupancy of these sites was determined at room temperature by neutron diffraction and is given in Table 6. Again, the resulting fits and the corresponding spectral parameters are consistent with the electronic properties of $\mathrm{Nd}_{18} \mathrm{Li}_{8} \mathrm{Fe}_{4} \mathrm{CoO}_{39}$, which has iron(III) ions on the $8 e$ and $16 i$ crystallographic sites and iron(IV) ions on the $2 a$ site. 
The $25 \mathrm{~K}$ Mössbauer spectrum of $\mathrm{Nd}_{18} \mathrm{Li}_{8} \mathrm{Fe}_{4} \mathrm{CoO}_{39}$ indicates the presence, $\sim 15 \%$ by area, of a magnetic sextet with a hyperfine field of $\sim 44 \mathrm{~T}$ and an isomer shift of $\sim 0.4$ $\mathrm{mm} / \mathrm{s}$, parameters that again are characteristic of iron(III).

The $4.2 \mathrm{~K}$ spectrum of $\mathrm{Nd}_{18} \mathrm{Li}_{8} \mathrm{Fe}_{4} \mathrm{CoO}_{39}$ has been fit with the superposition of three sextets, with hyperfine fields of $20(1), 51.5(5)$, and 47(2) T, assigned to the $2 a, 8 e$, and $16 i$ sites, respectively, with the relative areas constrained to the iron occupancy of these sites determined by neutron diffraction and given above. The remaining spectral parameters of these sextets are given in Table S1 (Supporting Information). Both isomer shifts and hyperfine fields ${ }^{6}$ are compatible with the presence of low-spin iron(IV) on the $2 a$ site and high-spin iron(III) on the $8 e$ and $16 i$ sites.

The temperature dependence of the $\mathrm{Nd}_{18} \mathrm{Li}_{8} \mathrm{Fe}_{4} \mathrm{CoO}_{39}$ isomer shifts and quadrupole splittings observed for the $2 a$, $8 e$, and $16 i$ sites and their weighted average values are shown in Figures S11 and S12 (Supporting Information), respectively. As expected, the three isomer shifts decrease with increasing temperature, and Debye model fits yield the solid line fits shown in Figure S11 and Debye temperatures of 634(17), 450(50), 620(70), and 510(40) $\mathrm{K}$ for the $2 a, 8 e$, and $16 i$ site isomer shifts and their weighted average, respectively. The somewhat higher value for the $2 a$ site results because this is the iron(IV) site with shorter bonds and the corresponding higher vibrational frequencies.

Between 25 and $295 \mathrm{~K}$, the quadrupole splittings of the $2 a, 8 e$, and $16 i$ sites are virtually constant. Consequently, in fitting the $4.2 \mathrm{~K}$ spectrum, see Figure S10 (Supporting Information), the values of the quadrupole splitting have been constrained to the values given in Table S1 (Supporting Information), and the values of $\theta$, the angle between the principal axis of the electric field gradient and the magnetic hyperfine field, have been adjusted, yielding 24(2), 46(1), and $53(2)^{\circ}$ for the $2 a, 8 e$, and $16 i$ sites, respectively. The $4.2 \mathrm{~K}$ line widths are $0.51(6), 0.50(3)$, and $0.4(1) \mathrm{mm} / \mathrm{s}$ for the $2 a, 8 e$, and $16 i$ sites, respectively. Again, these values represent a significant broadening as compared with both the line widths observed above $25 \mathrm{~K}$ and the instrumental line width of $0.25(1) \mathrm{mm} / \mathrm{s}$.

\section{Discussion}

The crystal structures of $\mathrm{Nd}_{18} \mathrm{Li}_{8} \mathrm{Fe}_{4} \mathrm{MnO}_{39}$ and $\mathrm{Nd}_{18} \mathrm{Li}_{8} \mathrm{FeMn}_{4} \mathrm{O}_{39}$ are clearly very similar to that of $\mathrm{Nd}_{18} \mathrm{Li}_{8} \mathrm{Fe}_{5} \mathrm{O}_{39}$. The absence of manganese from the prismatic sites is consistent with the structural chemistry of the onedimensional chain compounds $\mathrm{Ca}_{3} \mathrm{Co}_{1.04} \mathrm{Mn}_{0.96} \mathrm{O}_{6}{ }^{8}$ and $\mathrm{Ca}_{3} \mathrm{ZnMnO}_{6},{ }^{9}$ although there is some disagreement about the cation distribution in, and the exact composition of, the phase with the nominal composition $\mathrm{Ca}_{3} \mathrm{NiMnO}_{6} \cdot{ }^{9}{ }^{10}$ It is unfortunate that the relative concentration of iron and manganese on the $2 a$ site renders the average scattering length close to

(8) Choi, Y. J.; Yi, H. T.; Lee, S.; Huang, Q.; Kiryukhin, V.; Cheong, S. W. Phys. Rev. Lett. 2008, 100, 047601.

(9) Kawasaki, S.; Takano, M.; Inami, T. J. Solid State Chem. 1999, 145, 302.

(10) Bazuev, G. V.; Zubkov, V. G.; Berger, I. F.; Arbuzova, T. I. Solid State Sci. 1999, 1, 365. zero and necessitates the use of a constrained displacement parameter. However, it is clear from the neutron diffraction data that the iron and manganese cations do not order over the $2 a$ and $8 e$ octahedral sites in either composition. The iron distribution deduced from these data, including the presence of iron on the prismatic $16 i$ site for the composition $x=1$ only, was consistent with the Mössbauer spectral data. The mean cation position lies closer to the center of the prism than was the case in the manganese-free composition, although the quadrupole splitting observed in the Mössbauer spectra remains large. It is clear from the displacement parameters of $\mathrm{Nd} 1$ and $\mathrm{Nd} 2$ (Table 2) and from the bond lengths listed in Table 3 that the oxide polyhedron around the $\mathrm{Nd} 2$ site is more compact than that around $\mathrm{Nd} 1$. This raises the possibility that it might be possible to tune the occupancy of the octahedral and prismatic sites in this structure by using two different lanthanide cations to occupy the $\mathrm{Nd} 1$ and $\mathrm{Nd} 2$ sites. As in the case of both $\mathrm{La}_{18} \mathrm{Li}_{8} \mathrm{Rh}_{5} \mathrm{O}_{39}$ and $\mathrm{Nd}_{18} \mathrm{Li}_{8} \mathrm{Fe}_{5} \mathrm{O}_{39}$, the $\mathrm{O} 4$ site is disordered in $\mathrm{Nd}_{18} \mathrm{Li}_{8} \mathrm{Fe}_{5-x} \mathrm{M}_{x} \mathrm{O}_{39}$ for both $x=1$ and $x=4$. The bond length in the octahedron formed by this anion around the $2 a$ site in the composition $x=1$ is only $1.88 \AA$, and we assign the cations on this site to be $\mathrm{Mn}^{4+}$ and low-spin $\mathrm{Fe}^{4+}$, the latter spin-state assignment being consistent with the Mössbauer spectral hyperfine parameters. Charge balance then requires all of the transition-metal cations on the $8 e$ and $16 i$ sites to be trivalent. We have argued previously ${ }^{2}$ that the adoption by $\mathrm{Fe}^{4+}$ of the low-spin state can be ascribed to the high chemical pressure created by the small coordination polyhedron, and the short $\mathrm{Nd} 2-\mathrm{O} 4$ bond is further evidence of the internal pressure within the structure. The shortest $\mathrm{Nd}-\mathrm{O}$ bond length in $\mathrm{NdFeO}_{3}$ is 2.343(4) $\AA^{1 .}{ }^{11}$ However, the most striking structural feature of the $\mathrm{Nd}_{18} \mathrm{Li}_{8} \mathrm{Fe}_{5-x} \mathrm{M}_{x} \mathrm{O}_{39}$ series is that the unit cell parameter decreases with increasing manganese content. This suggests that, for example, the highspin $\mathrm{Fe}^{3+}$ cations that are known to occupy the $8 e$ sites of the $x=0$ composition are not simply replaced by high-spin $\mathrm{Mn}^{3+}$ cations, which are larger in size. Furthermore, the displacement parameters of the oxide anion O1 (Table 2) do not show the enhancement which would be expected to accompany local distortions of the $8 e$ coordination polyhedra; such distortions might be expected if a Jahn-Teller active cation was to be introduced. An unexpected but selfconsistent explanation is that $\mathrm{Mn}^{3+}$ enters the structure in the low-spin state. This unusual species has been predicted to exist in the hypothetical rhombohedral phase of $\mathrm{LiMnO}_{2},{ }^{12}$ and it is said to occur in $\mathrm{LiMn}_{0.65} \mathrm{Cr}_{0.35} \mathrm{O}_{2}$. A spin crossover has been observed in $\mathrm{CsMnF}_{4}$ under a pressure of $37 \mathrm{GPa}$, with a concomitant loss of the Jahn-Teller distortion. ${ }^{13}$ The presence of low-spin $\mathrm{Mn}^{3+}$ in $\mathrm{Nd}_{18} \mathrm{Li}_{8} \mathrm{Fe}_{5-x} \mathrm{M}_{x} \mathrm{O}_{39}$ is thus consistent with our previous ${ }^{2}$ suggestion that the transitionmetal polyhedra in this structure are subjected to an effective chemical pressure of $\sim 30 \mathrm{GPa}$. That suggestion was based

(11) Marezio, M.; Remeika, J. P.; Dernier, P. D. Acta Crystallogr. 1970, B26, 2008.

(12) Huang, Z. F.; Du, F.; Wang, C. Z.; Wang, D. P.; Chen, G. Phys. Rev. B 2007, 75, 054411 .

(13) Aguado, F.; Rodriguez, F.; Nunez, P. Phys. Rev. B 2007, 76, 094417. 
on the observation, by Mössbauer spectroscopy, of the isoelectronic $\mathrm{Fe}^{4+}$ species in the low-spin state in the $x=0$ composition. Our hypothesis is also consistent with the shortening of the metal-to-oxygen bonds around the $8 e$ sites that occurs as $x$ increases (Table 3 ). This reduction in size also accounts for the absence of $\mathrm{Li}^{+}$from the $8 e$ site when $x=4$.

The Curie constants derived from the dc magnetic susceptibility data collected over the temperature range 100 $<T / \mathrm{K}<300$ (Table 1) are also consistent with the presence of low-spin $\mathrm{Mn}^{3+}$ on the $8 e$ sites. Although the negative values of the Weiss temperature suggest that antiferromagnetic interactions dominate in these compounds, our data taken as a whole show that the low-temperature behavior is complex. The inequivalence of the ZFC and FC dc susceptibilities below $T_{\mathrm{f}}$, the observation of hysteresis in $\mathrm{M}(\mathrm{H})$, and the absence of saturation in $\mathrm{M}(\mathrm{H})$ are all consistent with the adoption of a spin-glass-like ground state. The frequency dependence of $T_{\mathrm{f}}$ and the coincidence of $\chi_{\text {max }}^{\prime}$ and $\left(\mathrm{d} \chi^{\prime \prime} / \mathrm{d} T\right)_{\text {min }}$ in the ac susceptibility support this assignment, as does the absence of magnetic Bragg scattering in the neutron diffraction pattern collected from the $x=1$ sample at $3.3 \mathrm{~K}$. The values of $\kappa$ listed in Table 1 are also consistent with the formation of an insulating spin glass. The magnitude of the susceptibility close to $T_{\mathrm{f}}$ initially increases as $\mathrm{Mn}$ is introduced into the system and then decreases as the concentration of low-spin $\mathrm{Mn}^{3+}$ increases. The initial increase can be attributed to short-range ferromagnetic coupling between manganese and iron cations having different electronic configurations, for example, low-spin $\mathrm{d}^{4}$ and highspin $\mathrm{d}^{5}$, together with the reduction in the number of pairs of iron atoms in neighboring $16 i$ and $8 e$ sites coupling via antiferromagnetic direct exchange. ${ }^{2}$ The overall decrease in the ZFC susceptibility on cooling below $T_{\mathrm{f}}$ shows that the neodymium cations are also involved in the spin-freezing process. The maximum in the ac susceptibility broadens as the manganese concentration increases. This broadening, perhaps most clearly seen in the low-frequency behavior of $\chi^{\prime \prime}$ in the case of $\mathrm{Nd}_{18} \mathrm{Li}_{8} \mathrm{FeMn}_{4} \mathrm{O}_{39}$, might be attributable to the presence of two distinct transitions, one involving the neodymium cations and the other the transition-metal cations, with a concentration-dependent temperature difference between them. The spin-glass-like behavior is likely to originate from the magnetic frustration present within the disordered cation array. The magnetic properties of $\mathrm{Nd}_{18} \mathrm{Li}_{8} \mathrm{FeMn}_{4} \mathrm{O}_{39}$ suggest that there is sufficient frustration between the octahedral sites to cause this type of behavior, even when no magnetic cations are located on the prismatic 16i sites.

The temperature dependence of the Mössbauer spectra of $\mathrm{Nd}_{18} \mathrm{Li}_{8} \mathrm{Fe}_{4} \mathrm{MnO}_{39}$ is consistent with the above discussion. The onset of spin freezing is discernible in the spectrum collected at $25 \mathrm{~K}$ and the three fully developed, but substantially broadened, sextets that are observed at $4.2 \mathrm{~K}$. The spectrum collected at $25 \mathrm{~K}$ from $\mathrm{Nd}_{18} \mathrm{Li}_{8} \mathrm{FeMn}_{4} \mathrm{O}_{39}$ is also consistent with our arguments.

The behavior of the $\mathrm{Nd}_{18} \mathrm{Li}_{8} \mathrm{Fe}_{5-\mathrm{x}} \mathrm{Co}_{\mathrm{x}} \mathrm{O}_{39}$ system is similar to that described above, although there are a number of important differences. We were not able to produce a pure sample having $x>3$, and so the range of cobalt-containing compositions studied is less extensive. This limitation is not surprising given that our previous attempts ${ }^{2}$ to prepare $\mathrm{Nd}_{18} \mathrm{Li}_{8} \mathrm{Co}_{5} \mathrm{O}_{39}$ resulted in the formation of cation-deficient $\mathrm{Nd}_{18} \mathrm{Li}_{8} \mathrm{Co}_{4} \mathrm{O}_{39}$. The formation of $\mathrm{LiCoO}_{2}$ during our attempted synthesis of $\mathrm{Nd}_{18} \mathrm{Li}_{8} \mathrm{FeCo}_{4} \mathrm{O}_{39}$ is an indication that a cation-deficient phase might again be forming. This hypothesis will be tested in future experiments. Analysis of the diffraction and Mössbauer spectral data showed that, when $x=1$, the $2 a$ site is occupied only by iron and that all of the cobalt atoms lie on $8 e$ sites. Together with the Curie constants (Table 5), these data show that low-spin $\mathrm{Fe}^{4+}$ occupies the $2 a$ site, with high-spin $\mathrm{Fe}^{3+}$, low-spin $\mathrm{Co}^{3+}$, and $10 \%$ lithium occupying the $8 e$ sites; $5 \%$ of the $16 i$ sites are occupied by high-spin $\mathrm{Fe}^{3+} . \mathrm{Nd}_{18} \mathrm{Li}_{8} \mathrm{Fe}_{4} \mathrm{CoO}_{39}$ is thus the only one of the compositions studied that shows sought-after cation ordering over the $2 a$ and $8 e$ sites. Even in this case, the $2 a$ site is occupied by $25 \%$ of the more-abundant metal (iron) rather than by all of the minor component (cobalt), and consequently transition-metal disorder persists on the $8 e$ site. The decrease observed in the unit-cell parameter as iron is replaced by cobalt in $\mathrm{Nd}_{18} \mathrm{Li}_{8} \mathrm{Fe}_{5-x} \mathrm{Co}_{x} \mathrm{O}_{39}$ is then to be expected. The $\mathrm{Fe}^{4+}-\mathrm{O} 4$ bond length is very similar to that reported previously in $\mathrm{Nd}_{18} \mathrm{Li}_{8} \mathrm{Fe}_{5} \mathrm{O}_{39}$, as is the isomer shift in the Mössbauer spectrum. The bond lengths around the other cation sites, including those where neodymium is located, all lie within the expected range. The short Nd2-O4 bond length seen in the manganese-containing analogues is not reproduced in $\mathrm{Nd}_{18} \mathrm{Li}_{8} \mathrm{Fe}_{4} \mathrm{CoO}_{39}$.

The cation distribution proposed above for the composition $x=1$ is consistent with the magnetic data collected on the other compositions. In all cases, antiferromagnetic interactions are dominant, but the inequivalence of the ZFC and FC dc susceptibilities below $T_{\mathrm{f}}$, the observation of hysteresis in $\mathrm{M}(\mathrm{H})$, and the frequency dependence of the ac susceptibility all indicate that, as in the case of the manganese analogues, these compounds show spin-glass-like behavior below $T_{\mathrm{f}}$. This is also consistent with the Mössbauer spectral data collected for the sample $x=1$. This behavior is again likely to be a consequence of magnetic frustration, which is, in turn, brought about by the disordered cation distribution. Figure 13 shows that the extent of the irreversibility decreases as the cobalt content increases. Interestingly, of all of the compounds in this family studied to date, only in the case of the cation-deficient $\mathrm{Nd}_{18} \mathrm{Li}_{8} \mathrm{Co}_{4} \mathrm{O}_{39}$ has the magnetic susceptibility suggested the presence of a ground-state showing long-range magnetic order. It is also interesting that the value of $T_{\mathrm{f}}$ decreases more rapidly with increasing $x$ for the cobalt-containing $\mathrm{Nd}_{18} \mathrm{Li}_{8} \mathrm{Fe}_{5-x} \mathrm{M}_{x} \mathrm{O}_{39}$ compositions than for the manganese analogues. This decrease can be ascribed to an increase in the concentration of diamagnetic, low-spin $\mathrm{Co}^{3+}$ and the value $(2.3 \mathrm{~K})$ observed when $x=3$ is the same as the proposed Néel temperature of $\mathrm{Nd}_{18} \mathrm{Li}_{8} \mathrm{Co}_{4} \mathrm{O}_{39}$. This result is consistent with our previous suggestion ${ }^{2}$ that the transition in the cobalt-rich compositions is largely driven by the cations on the lanthanide sublattice.

The study described above has extended the range of compounds known to adopt the $\mathrm{La}_{18} \mathrm{Li}_{8} \mathrm{Rh}_{5} \mathrm{O}_{39}$ crystal 
structure. We have shown that the $2 a$ and $8 e$ sites can be occupied by more than one d-block element, but we have been unable to induce the cation ordering that we believe to be a prerequisite for the formation of a ferrimagnetic ground state. Perhaps the most interesting outcome of this work is the observation of low-spin $\mathrm{Mn}^{3+}$ in a mixed-metal oxide. Our explanation for the presence of this cation species relies on the presence of a high internal pressure, possibly generated by a size mismatch between the $\mathrm{Nd}-\mathrm{O}$ framework and the chains of coordination polyhedra which occupy the channels within the framework. We shall investigate this further by studying compositions in which neodymium is replaced by other lanthanide cations, both larger and smaller.
Acknowledgment. The authors thank Dr. M. Sougrati for help in obtaining some of the Mössbauer spectra. S.E.D. thanks EPSRC and Somerville College, Oxford, for financial support. F.G. thanks the National Fund for Scientific Research, Belgium, for Grant 1.5.064.05. The authors are also grateful to ILL, Grenoble, for the provision of neutron facilities.

Supporting Information Available: Additional figures are provided. This material is available free of charge via the Internet at http://pubs.acs.org.

IC802035V 